PRESCHOOL CHILDREN'S PERCEPTIONS OF OTHER CHILDREN BASED ON BODY SIZE

by

Wei Su

B.A. (Honours), Queen's University, Kingston, ON, 2007

A Major Research Paper

Presented to Ryerson University

In partial fulfillment of the requirements for the degree of

\author{
Master of Arts \\ In the Program of \\ Early Childhood Studies
}

Toronto, Ontario, Canada, 2008

(C) Wei Su 2008 

I hereby declare that I am the sole author of this major research paper.

I authorize Ryerson University to lend this paper to other institutions or individuals for the purpose of scholarly research.

I further authorize Ryerson University to reproduce this paper by photocopying or by other

means, in total or in part, at the request of other institutions or individuals for the purpose of scholarly research. 



\title{
PRESCHOOL CHILDREN'S PERCEPTIONS OF OTHER CHILDREN BASED ON BODY
}

\author{
SIZE \\ (C) Wei Su 2008 \\ Master of Arts \\ Early Childhood Studies \\ Ryerson University
}

\begin{abstract}
Overweight individuals are highly stigmatized in society. The purpose of the study is to determine if preschool children perceive overweight children to have more negative characteristics than non-overweight children. Interviews were conducted with 42 preschool children from 32 to 70 months old. Children listened to four stories about an interaction between two children, in which one child demonstrated socially unacceptable behaviour and one who demonstrated prosocial behaviour. Stories were presented along with two target figures (one target $=$ overweight, one target $=$ non-overweight $)$. Results showed that children perceived the overweight target figure as 'mean' more often than 'nice'. Same-gender overweight figures were more negatively perceived than overweight figures of the opposite gender. Male children also labeled overweight target figures as 'mean' more often than female children. No age differences were present. The findings of the study may be significant for the development of programs that will prevent or decrease negative body image attitudes and body stigmatization in order to create inclusive learning and social environments where all children are accepted, included and gain a sense of belonging regardless of their body shape or size.
\end{abstract}

Keywords: weight; stigmatization; diversity; early childhood; inclusion; gender; culture; age 



\section{Acknowledgement}

Writing the major research paper has been a challenging experience and could not have been completed without the support and encouragement from faculty, family and friends.

I would like to express my deepest gratitude to my supervisor, Aurelia Di Santo, for her sound advice, patient guidance, support and encouragement from the formulation stages of the paper until the final draft.

I would also to thank Patricia Corson, my second reader, and Rachel Berman, the Chair of my defense committee, for dedicating time to review my major research paper. Thank you for your valuable suggestions and constructive feedback.

To the faculty of Early Childhood Studies, thank you for assistance throughout the year and encouraging me to pursue this major research paper.

To my mom, dad, grandma and grandpa thank you for being your steadfast support. To my friends and colleagues from the Master's of Early Childhood Studies program, thank you for your moral support and for making this year fun and memorable. Ron, thank you for your patience and for believing in me.

Most importantly, I would like to thank all the staff at the various early learning and childcare centres and children's parents for allowing this research to take place. To all children involved in the study, thank you for sharing your thoughts with me. Without you, this research would not have been possible. 



\section{Table of Contents}

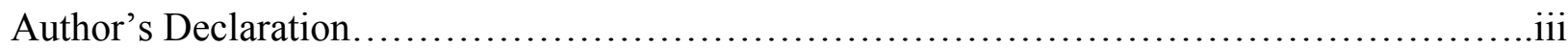

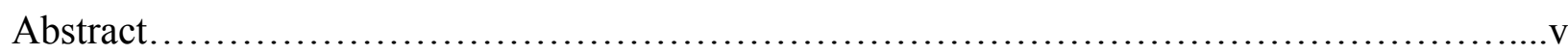

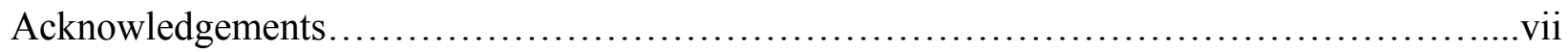

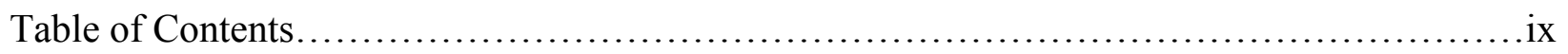

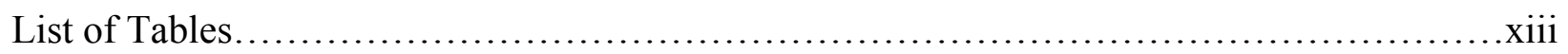

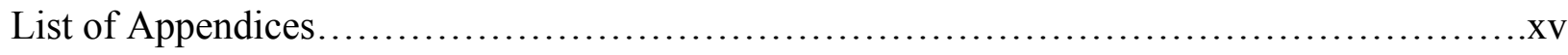

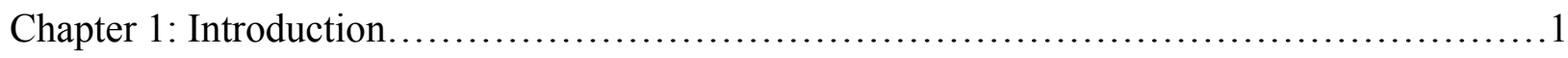

Chapter 2: Literature Review and Theoretical Context....................................

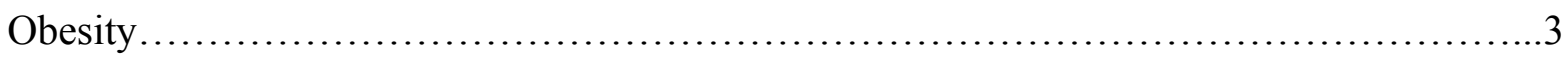

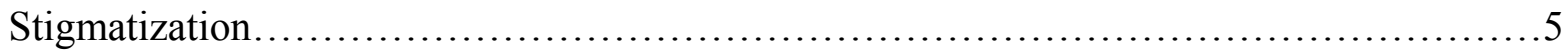

Theoretical Framework........................................................... 17

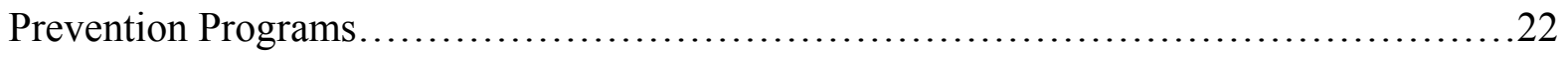

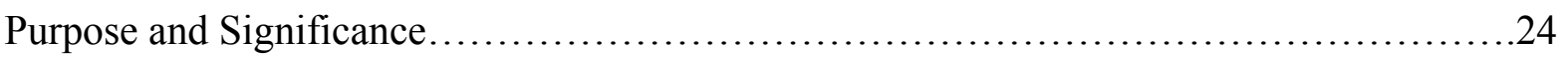

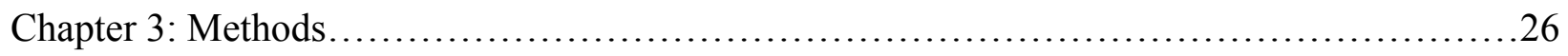

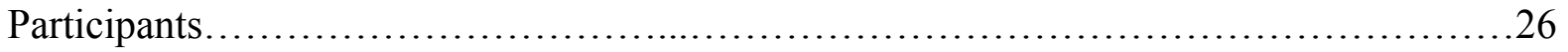

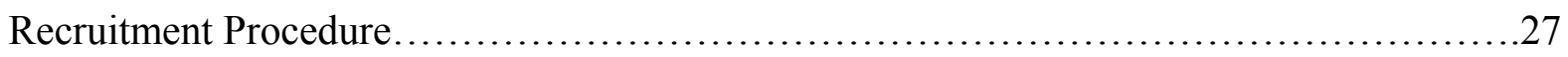

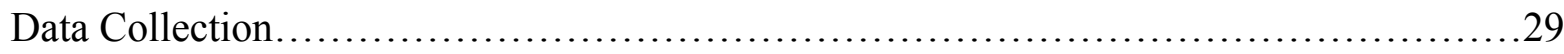

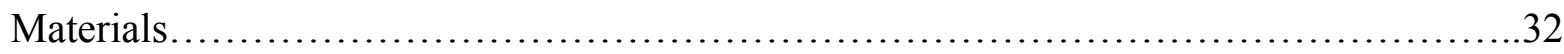

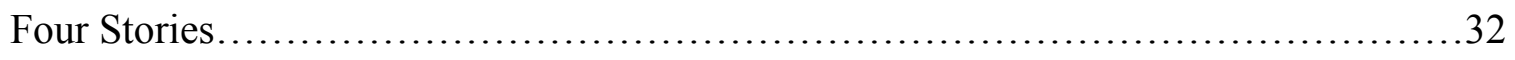

Target Figures................................................................ 33

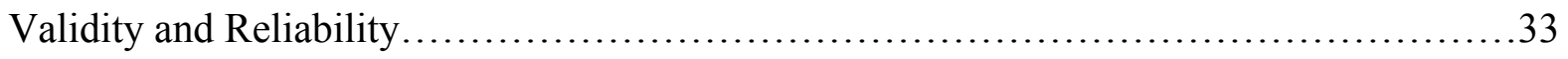

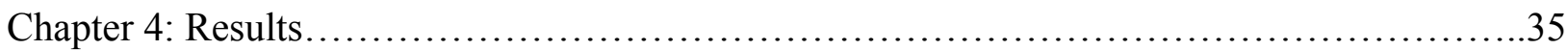




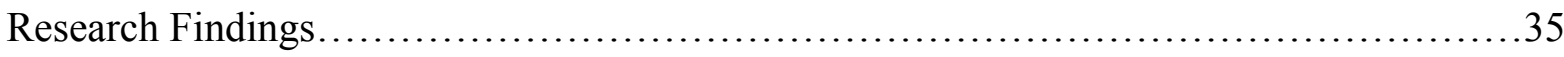

Question 1: Children's Perceptions of Weight.........................................35

Story 1 - Male Fantasy Story .............................................36

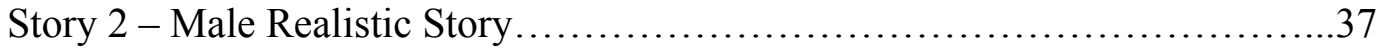

Story 3 - Female Fantasy Story ............................................ 37

Story 4 - Female Realistic Story .............................................

Overall Story Effect....................................................... 38

Question 2: Children' Perceptions of Weight by Age.................................38

Question 3: Children's Perception of Weight by Gender..............................39

Question 4: Cross-Gender Attributions .........................................40

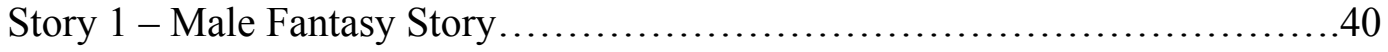

Story 2 - Male Realistic Story ............................................ 40

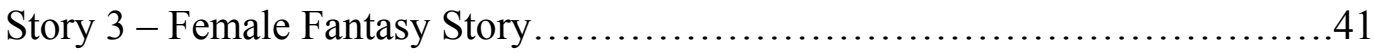

Story 4 - Female Realistic Story ...........................................41

Question 5: Children's Perceptions of Weight by Ethnicity...........................42

Question 6: Children's Rationales...............................................44

Perceptions of Physical Attributes of Overweight Children.....................45

Perceptions of Behavioural Attributes of Overweight Children..................47

Perceptions of Emotional Attributes of Overweight Children.....................48

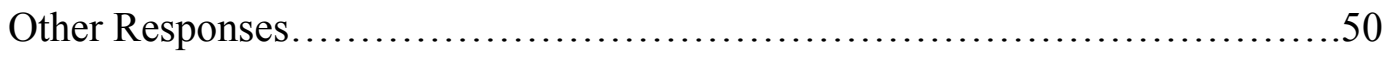

Review of General Findings...................................................50

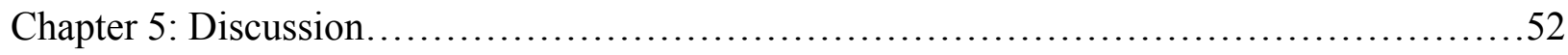

Children's Perceptions of Weight....................................................52 
Children's Perceptions of Weight by Age........................................53

Children's Perceptions of Weight by Gender......................................55

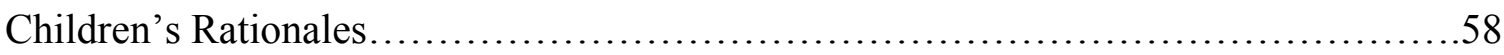

Recommendations for Weight Acceptance ......................................6 60

Microsystems - Early Educators and Parents.................................61

Mesosystems - Home and School Environments.............................62

Exosystems - School Boards............................................64

Macro and Chronosystems - Mass Media..................................65

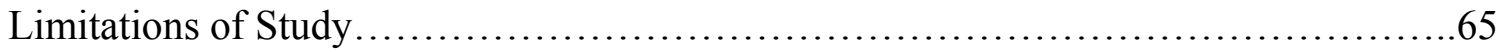

Recommendations for Future Research..............................................66

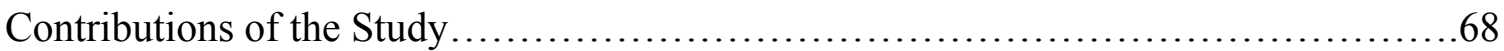

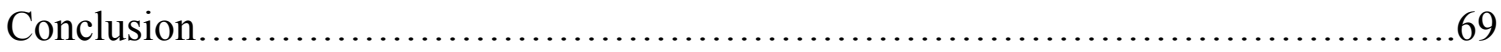

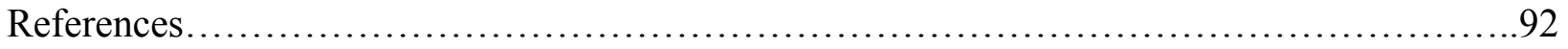





\section{Tables}

Table 1. Frequencies and Percentages of Overweight Target Figures Categorized as 'Mean'....36

Table 2. Overweight Target Figure Labeled as 'Mean' by Age..............................39

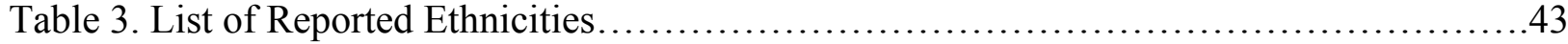





\section{List of Appendices}

Appendix A. Board of Directors and/or Owner/Operator Letter of Information............... 71

Appendix B. Board of Directors and/or Owner/Operator Consent Form................... 75

Appendix C. Parental Letter of Information and Consent Agreement...................... 77

Appendix D. Study Flyer...................................................... 81

Appendix E. Demographic Questionnaire of Child................................... 83

Appendix F. Four Stories and Follow-Up Questions................................. 85

Appendix G. Target Figures................................................... 87

Appendix H. Permission from Tillman.............................................. 91 

Chapter 1: Introduction

Thinness has become the ideal standard of beauty in North American society and obesity is met with many negative connotations. Overweight children are often associated with character traits such as being lazy or lacking willpower (Pitman \& Kaufman, 2000). In the past several decades, perceptions of body shape and weight have changed dramatically in western society. Overweight individuals were once associated with wealth, the ability to bear children, and being able to survive famine, however, today they are associated with many negative characteristics (Powdermaker, 1997). Also, obesity was once seen as a "symbol within a system of prestige" (MacDermott, 2007). In visual arts, slightly overweight female forms were the norm through the ages and can be witnessed through some of the earliest known cultural artifacts from European and Mediterranean societies (Pitman \& Kaufman, 2000; MacDermott, 2002). However today, "the overly thin standard of beauty [is] becoming more and more rigorous" even amongst young children (Tillman, 2003, p. 17).

Children who are overweight often face societal prejudices attributed to their weight (Latner \& Stunkard, 2002; Tiggemann \& Anesbury, 2000). While obesity is increasing, society is also becoming more preoccupied with weight and body size. Alarmingly, 55\% of girls and $35 \%$ of boys between the ages of 8-to-10 are dissatisfied with their body size (Wood, Becker, \& Thompson, 1996). Additional research has recognized that some children as young as 4-6 years of age are dissatisfied with their bodies and striving for thinness (Lunde, Frisen \& Hwang, 2006).

To date, there is no definition for childhood or adolescent obesity that is internationally accepted (Mullen \& Shield, 2004). Although there is no standardized measure to determine obesity for both adults and children, the most common measurement of obesity used is the body mass index (BMI) (MacDermott, 2007). BMI is calculated by determining an individual's weight 
in kilograms divided by the square of height in meters $\left(\mathrm{kg} / \mathrm{m}^{2}\right.$ ) (World Health Organization, 2008). The World Health Organization has indicated that individuals with BMIs over $25 \mathrm{~kg} / \mathrm{m}^{2}$ are considered overweight while individuals with BMIs over $30 \mathrm{~kg} / \mathrm{m}^{2}$ are considered obese. While the BMI is the most common measurement of obesity, there is no clear distinguishing definition between "overweight" and "obesity" amongst researchers worldwide, therefore these two terms are often used interchangeably throughout the literature (MacDermott, 2007). Therefore for the purpose of this study, the term obesity and overweight will be used interchangeably. It should be noted that the definitions and methods used to determine obesity may differ between studies throughout the literature (MacDermott, 2007).

The chapter that follows will provide a critical review of the literature regarding obesity prevalence, etiology and the health issues associated with obesity. Following is a discussion of stigmatization and how negative perceptions or actions can also have negative ramifications on the psychological, emotional, physical, and social health of overweight children. In addition, Bronfrenbrenner's social ecological theory will be used as a theoretical framework for the study. The review will conclude with specific research questions that will be examined in this Major Research Paper. 


\section{Chapter 2: Literature Review and Theoretical Context}

\section{Obesity}

Obesity is becoming a major health problem and is on the rise (Dixey, Sahota, Atwal \& Turner, 2001; Jansen, Smeets, Boon, Nederkoorn, Roefs \& Mulkens 2007). Globally, there are more than one billion overweight adults and the World Health Organization has coined the term "globesity" to refer to global obesity (World Health Organization, 2008). Since the 1980s, obesity rates have increased three-fold or more in many areas of the world including North America, Australia, China, Eastern Europe, the Middle East, the Pacific Islands, and the United Kingdom (World Health Organization, 2008). In Canada, according to the Canadian Community Health Survey (CCHS) $2000-2001,47.4 \%$ of the population $(55.6 \%$ of men and $39.2 \%$ of women) exceeded the recommended guidelines for healthy weight (Raine, 2004).

In addition, in the United States of America, the number of children who are overweight has doubled over the past two decades leading to growing numbers of children who are overweight present in the school system (Neumark-Sztainer, Story \& Harris, 1999; Snethen \& Broome, 2007). It is estimated that worldwide, there are approximately 22 million children under the age of five who are overweight (World Health Organization, 2008). In Canada, according to the National Longitudinal Survey of Children and Youth (NLSCY), from 1981 to 1996, the prevalence of overweight and obesity tripled among boys seven to thirteen years of age from $10.6 \%$ to $32.6 \%$ and doubled among girls seven to thirteen years of age from $13.1 \%$ to $26.6 \%$ (Raine, 2004).

The origin of obesity is multifactorial and both heredity and environmental factors play a pivotal role in the obesity pandemic (Mullen \& Shield, 2004). Genetics affect BMI from 30\% to $75 \%$ and parental obesity is the strongest predictor of adulthood obesity (Mullen \& Shield, 
2004). However, even though obesity is closely linked with genetic factors, genetics within a population do not change quickly (Mullen \& Shield, 2004). Therefore, the large increases in obesity seem to be attributed to environmental factors such as physical inactivity and increased dietary intake of food with poor nutritional content, energy-dense food, and food with high levels of sugar and saturated fats (Mullen \& Shield, 2004; World Health Organization, 2008). Data from the Canadian Community Health Survey (CCHS) in 2000-2001 has shown that fruit and vegetable consumption is negatively correlated with being overweight, meaning that a lower intake of fruits and vegetables may lead to a higher probability of being overweight (Raine, 2004). In addition, data from the 1998-1999 National Population Health Survey (NPHS) has shown that $76.6 \%$ of women and $73.9 \%$ of men are not active enough to reap the health benefits of physical activity (Raine, 2004).

With obesity, a variety of physical and mental health issues arise. The long term health consequences of obesity include Type 2 diabetes, hyperlipidemia, hypertension, early maturation and orthopedic problems (Mullen \& Sheild, 2004). Approximately 90\% of individuals with Type 2 diabetes are obese (World Health Organization, 2008). Other long term consequences of obesity are an increased risk of breast, colon, prostate, endometrium, kidney and gallbladder cancer (World Health Organization, 2008). In addition, obesity is a major risk factor for coronary heart disease, stroke, musculoskeletal disorders, cardiovascular diseases and respiratory symptoms (Raine, 2004). Although many of the diseases related to obesity will take many years to develop, there are also many immediate health conditions that childhood obesity creates such as recurrent headaches, asthma, sleep disorders such as sleep apnea, early puberty and menarche (Mullen \& Sheild, 2004). Also alarmingly, from 1985 to 2000, more than 57,000 deaths among 20-to-64 year olds in Canada were attributed to being overweight and obese (Raine, 2004). 


\section{Stigmatization}

In addition to various health problems, many overweight children and adults are socially marginalized or discriminated against and face psychological problems such as low-self esteem and depression (Raine, 2004; Mullen \& Sheild, 2004; Tiggemann \& Anesbury, 2000). Overweight children are also often perceived to embody negative characteristics by their peers (Jansen et al., 2006; Kostanski \& Gullone, 2006; Neumark-Sztainer, et al., 1999; Smith \& Niemi, 2007). Across age groups, children as young as three-years-old characterize overweight children as having many negative characteristics such as being lazy, unattractive, unhappy, unpopular, unfriendly, sloppy (Tiggeman \& Anesbury, 2000; Turnbull, Heaslip \& McLeod, 2000; Kraig \& Keel, 2001) and having lower intelligence than their average-weight counterparts (Kraig \& Keel, 2001; Schwartz, Chambliss, Brownell, Blair \& Billington, 2003). In addition, children rate their overweight peers as being the least desirable playmates and least well liked peers (Strauss, Smith, Frame \& Forehand, 1985). Studies have consistently demonstrated that when children are asked to attribute characteristics to figures of overweight and non-overweight children, overweight figures are consistently labeled with less favorable attributes (e.g., Birbeck \& Drummond, 2005; Cramer \& Steinwert, 1998; Counts, Jones, Frame, Jarvie \& Strauss, 1986; Kraig \& Keel, 2001; Latner, Stunkard \& Wilson, 2005; Lerner \& Korn, 1972; Pine, 2001; Tiggemann \& Anesbury, 2000; Staffieri, 1967; Tillman, Kehle, Bray, Chafouleas \& Grigerick, 2007; Turnbull et al., 2000).

In a classic study by Richardson, Goodman, Hastrof \& Dornbusch (1961), children between the ages of 10 and 11 were asked to rank in order pictures of children who they liked from most to least. The children depicted in the pictures were: a child with no physical handicap, a child with crutches, a child sitting in a wheelchair, a child with a missing left hand, a child with 
a facial disfigurement, and an obese child. Richardson et al. (1961) found that children favored pictures of children who had one of four disabilities (child with crutches, child in wheelchair, child with facial disfigurement, and child with missing hand) more than the obese child. The child with no physical disabilities was rated as the favorite (Richardson et al. 1961). Replications of the study have also found similar results (e.g., Goodman, Dornbusch, Richardson \& Hastorf, 1963; Latner, Stunkard, 2002; Latner et al., 2005; Sigelman, Miller \& Whitworth, 1986). Even when the replication studies were conducted with participants of different ages, gender and ethnicities, results of all the replications studies have shown that obesity is highly stigmatized in relation to physical disabilities. Researchers have speculated that obese individuals may be stigmatized partially because they are blamed for their condition (e.g., Latner et al., 2005). The ideology of blame is when overweight individuals are held responsible for their weight and the negative consequences that they face due to their weight (Greenleaf \& Weiller, 2005). In the Richardson et al. (1961) study and replication studies, it is possible that children with disabilities were not seen as being responsible for their disability but rather as victims while overweight individuals were seen as solely responsible for their condition. Since being overweight is highly stigmatized, many individuals may attribute the lack of exercise or not eating well with obesity although there are many genetic factors that have been linked with obesity.

In studies by Cramer and Steinwert (1998) and Tillman et al. (2007) preschool and elementary children were asked to listen to four short stories. Two stories are about boys and two stories are about girls. In each story, one child demonstrates socially unacceptable behaviour, while the other child of the same gender demonstrates prosocial behaviour. Children were then shown pictures of an overweight and non-overweight boy or girl and were asked to point to which figure represented the 'nice' child in the story and which child represented the 'mean' 
child in the story. The term 'nice' is used since studies have shown that young children "may use the term 'nice' as an indication of their positive feelings about someone rather than as a description of what that person is generally like" (Heyman \& Gelman, 1999, p. 605; Ruble \& Dweck, 1995). Both studies found that both boys and girls were more likely to identify the overweight child as the 'mean' child in the story (Cramer \& Steinwert, 1998; Tillman et al., 2007).

Additionally, in a study conducted by Birbeck \& Drummond (2005), five and six year old children's beliefs about their bodies and attributions of others based on body image were explored. Children were given nine images $(1=$ very thin, $9=$ obese $)$ and were asked to identify which figure most accurately resembled their own body size and which image was their ideal. Using the same figures, children were asked to select three of the figures to invite to their birthday party. As well, children were asked to explain their choice of some figures and the omission of others. The study found that children at this age already chose an ideal body size that was different than their actual size. Also significant, children in the study did not want to invite the larger figures to their birthday party for various reasons, such as they are "nasty", "mean" and "bullies" (Birbeck \& Drummond, 2005).

The literature has documented gender differences in perceptions of overweight individuals. Some studies have documented that overweight female figures were attributed with more negative characteristics than overweight male figures (Pine, 2001; Turnbull et al., 2000). In a replication of Richardson et al's (1961) study, Latner \& Stunkard's (2002) results highlighted that in a group of fifth and sixth graders, girls tend to favour overweight children less than boys. The same study showed that boys were more negative towards children with functional disabilities (e.g., wheelchair, child with missing hand) while girls had more negative perceptions 
of children with appearance-related disabilities (e.g., overweight, disfigured face) (Brumberg, 1998; Latner \& Stunkard, 2002; Richardson et al., 1961; Goodman et al., 1963; Sigelman, Miller \& Whitworth, 1986). Children in the Latner and Stunkard (2002) study were in grade five and six and the researchers suggest that a greater focus of athletics for boys and esthetics for girls may have been present throughout this stage of development which led to differences in perceptions between genders. In addition, other studies have also concluded that girls tend to have more negative views of overweight peers than boys (Latner et al., 2005; Pine, 2001; Turnbull et al., 2000). In contrast, some research has also documented no gender differences in the perception of overweight individuals, with both genders perceiving overweight individuals to have negative characteristics (e.g., Latner et al., 2005; Tillman et al., 2007). For example, Tillman et al.'s (2007) study had participants from the second and third grade, Latner and Stunkard's (2002) study consisted of participants from grade five to six, while Stunkard et al., (2005) study consisted of university students. Therefore, since all the studies have used participants of various ages, perhaps age of participants or participants' stage of development played a part in accounting for gender differences found between studies.

Also interesting were the results from Cramer and Steinwert's (1998) study which documented a "stronger cross-gender than same-gender stigmatism" (p. 434). For example, boys view overweight girls more negatively than overweight boys and vice versa. Cramer and Steinwert's (1998) study indicated that "as far as we are aware, this is the first study to investigate both cross-gender and same-gender stigmatism in the same children" (p. 434). Although Cramer and Steinwert's (1998) methodology was replicated in Tillman's (2003) study, no cross gender effects were found. Perhaps due to the difference in age, with one preschool and one elementary population, development may have played a role in the difference of gender 
effects. Tillman (2003) has speculated that perhaps very young children may have more negative feelings towards peers of the opposite gender regardless of weight. Developmental research has shown that gender segregated play can be observed even with preschool children and becomes most prominent between the ages of 8 and 11, and then declines slowly thereafter, especially when adolescents begin dating (Siegler, Deloache, Eisenberg \& 2003). Therefore based on developmental research, it would be expected that Tillman's (2003) study would yield stronger cross-gender effects than Cramer and Steinwert's (1998) study. However, since Tillman's study had an unequal distribution between male $(N=13)$ and female $(N=21)$ participants, the sample size may have affected the results.

In the Cramer and Steinwert (1998) study, results indicated that older preschool children had significantly more negative views of overweight children than younger preschool children. Similarly, another study found that participants from nursery school to third grade had more negative responses about overweight children as participant's age increased which suggests a rise in stigmatization over the course of development (Sigelmann et al., 1986). This will be important for informing curriculum since gender differences may require children at different ages to receive various types of programming to effectively address acceptance and body weight issues. Interestingly, although stigmatization by children increases with age, studies have also found that adults become more tolerant of overweight people (Latner et al., 2005).

Although researchers have noted that overweight children are stigmatized in studies which comprise of choosing between figures, some researchers have questioned whether children react to pictures of overweight figures differently than they would to real overweight individuals (e.g., Cramer \& Steinwert, 1998; Jarvie, Lahey, Graziano \& Framer, 1983; Tillman et al., 2007). These researchers are suggesting that although children may perceive overweight children 
negatively when seeing pictures and while asked questions, the same children may not actually behave negatively towards overweight children regardless of whether negative perceptions may or may not exist. For example, a child may say something negative about an overweight child in a picture but may not make the same comment if the overweight child in the picture was a real child. Therefore research must be conducted to explore how overweight children are treated in real life.

Some studies have shown that negative stigmatization does indeed exist for overweight children. In a qualitative study conducted by Larkin and Rice (2005), female students in grades seven and eight participated in workshops and interviews about body image and body or weight harassment. In the interviews, female students indicated that comments about weight are prevalent in the school system, especially comments about being overweight (Larkin \& Rice, 2005). Additionally, a qualitative study by Dixey et al. (2001), involved 11-year old children from the United Kingdom in focus group discussions. Through the discussions, children talked about the pressures to be a certain weight, how overweight children were often picked on, bullied and had few friends (Dixey et al., 2001). The study also concluded that children "were kinder to fat children in the abstract but acknowledged that their fat classmates were picked on" (Dixey, et al., 2001, p. 213). Furthermore, Kostanski \& Gullone's (2007) study of students from grades two to four, showed that both overweight and underweight children experienced and reported being teased. In another study, overweight and non-overweight children filled out psychological questionnaires which showed that overweight children reported more frequent, prevalent and upsetting appearance related teasing than non-overweight children (Hayden-Wade, Stein, Ghaderi, Saelens, Zabinski \& Wilfley, 2005). Hayden et al.'s (2005) research also indicated that the degree of teasing was associated with higher weight concerns, more loneliness, poorer self- 
perception of one's physical appearance, and a higher preference for sedentary and isolative activities. Similarly, a study with 13 to 18 year old girls found that obesity alone did not affect body image dissatisfaction in children, but obesity combined with peer teasing predicted appearance dissatisfaction (Thompson, Coovert, Richards, Johnson \& Cattarin, 1995). The study found that being overweight was a risk factor for being teased therefore teasing was associated with negative body image (Thompson et al., 1995).

Research has shown that overweight children have lower self-esteem, experience more shame, humiliation and teasing compared to their non overweight peers (Raine, 2004; Latner \& Stunkard, 2002). The stigmatization that overweight children face also affects their quality of life (Schwimmer, Burwinkle, Varni, 2003). Schwimmer et al. (2003) conducted a study where both child and parent filled out a health related Quality of Life (QOL) inventory. Health-related QOL "is a more comprehensive and multidimensional construct" which does not focus solely on aspects of self-esteem or psychosocial health, but encompassed physical (e.g., asthma, diabetes), emotional (e.g., depression), social (e.g., anxiety) and school functioning (e.g., number of school days missed). Results found that overweight children and adolescents had a significantly lower health-related QOL score compared to non-overweight children. Alarmingly, overweight children's health-related QOL score was similar to children and adolescents diagnosed with cancer (Schwimmer et al., 2003). This is a distressing finding since overweight children may be experiencing very low health-related QOL due in part to stigmatization from society. Although this study uncovered an important finding, the sample's demographics consisted of a large sample of Hispanic-American boys. Therefore, the results may be partially attributed to healthrelated QOL of a specific ethnicity rather than overweight individuals in general. In addition, the 
sample studied was "markedly obese" (Schwimmer et al., 2003, p.1818). Thus, it is not known whether children with varying degrees of obesity would yield the same results.

In Jansen et al.'s (2007) study, twenty overweight and sixteen non-overweight children between the ages of eight to twelve participated in the Situation Interpretation Test (SIT). The SIT included five ambiguous/neutral situations, for example, "You visit your family. Your aunt looks critically at you and says something to your mother. What is she saying?" (Jansen et al., 2007, p. 566). The second portion of the activity, the forced-choice SIT involved the same five stories but included a negative outcome to the situation, for example, "You visit your family. Your aunt looks critically at you and says something negative to your mother. What is she saying?" (Jansen et al., 2007, p. 566). Results showed that overweight children were more likely than non-overweight children to interpret neutral or negative events as being attributed to negative appearance or self-esteem related causes (Jansen et al., 2007). Research has also documented that stigmatization or stereotypes could create negative expectations regarding behaviours of overweight children which may negatively impact their social development (Counts, Jones, Frame, Jarvie \& Strauss, 1986). Therefore, because of stigmatization by society, overweight children may understand the negative expectations held towards overweight individuals and turn them into self-fullfilling prophecies (Snyder, Tanke \& Berscheild, 1997). As overweight children become adults, they continue to face stigmatization by society. Research has documented that overweight adults are less often accepted into high-ranking colleges than non-overweight peers even with equivalent qualifications (Canning \& Mayer, 1966). Results from the study showed that in the sample both overweight and non-overweight high school students were equally interested in attending high-ranking colleges, and there were no significant academic performance differences between the two groups. Canning \& Mayer 
(1966) speculate that high school teachers through writing letters of recommendations and college interviewers through interviews may have had prejudices towards overweight students and these negative aspects may have been transferred into overweight student's files which were reviewed by admission committees. In another study, differences in social behaviours between overweight and non-overweight women effected the impressions that others formed of them (Miller, Rothblum, Barbour, Brand \& Felicio, 1990). Overweight and non-overweight women were involved in a five minute telephone conversations with a college student, and neither party could see each other (Miller et al., 1990). The instructions of the phone conversation were to "try to get to know each other" and to talk freely about anything (Miller et al., 1990, p.370). At the end of the five minute conversation, women were rated by their conversation partners. In addition, judges who did not participate in any phone conversations listened to the audio-tapes of the phone interaction and rated participant social skills and attractiveness. Both phone partners and judges were unaware of the participants' weight or any physical features. Results showed that overweight women were rated as less likeable, less socially skilled, less physically attractive, were less friendly, and less comfortable than non-overweight women (Miller et al., 1990). Judges and phone partners formed a more negative impression of overweight women than the nonoverweight women. Although judges and phone partners were unable to see the participants, overweight women were still rated as less physically attractive than non-overweight participants. The researchers concluded that perhaps because of the stigma that overweight individuals face, their social interactions with others may be inhibited which may impede their ability to acquire social skills (Miller et al., 1990). Alternatively, overweight individuals may expect others to perceive them negatively and thus not use positive social skills (Miller et al., 1990). 
Raine (2004) also highlights evidence of discrimination against overweight individuals in educational institutions, employment and even by health professionals. Research has shown a relationship between lower socioeconomic status and obesity, with an increase of risk for obesity among groups with lower socioeconomic status (Raine, 2004). Since discrimination is evident against overweight individuals in many social settings, "such discrimination may contribute to reduced access to social, educational, and professional opportunities for obese people, thereby sustaining a vicious cycle in which obesity influences social class, while social class influences the prevalence of obesity" (Raine, 2004, p. 14). Therefore it is vital for research to continue to explore why and how stigmatization develops as well as ways to combat weight-based stigmatization since there are many negative consequences for both overweight children and adults due to stigmatization.

Some may assume that tolerance and stigmatization would decrease towards overweight individuals since obesity is becoming more common and widespread. However this does not seem to be the case (Latner \& Stunkard, 2002). In Latner and Stunkard's (2002) study, a replication of Richardson et al.'s (1961) classic study, male and female children in grades four and five were asked to rank their preference between six child figures from most favourable to least. The six figures consisted of a normal weight child, an obese child, a child with a facial disfigurement, a child in a wheelchair, a child with crutches, and a child with a missing hand (Latner \& Stunkard, 2002). Results were consistent with previous studies that found that children liked the obese child least (Latner \& Stunkard, 2002). However Latner \& Stunkard (2002) identified that the obese child figure was liked significantly less in their study than in Richardson et al.'s 1961 study. This indicates that obesity stigmatization has increased throughout the years. Stunkard \& Sobal (1995) suggested that "obesity remains the last socially acceptable form of 
prejudice, and obese persons remain perhaps the only group toward whom social derogation can be directed with impunity" (p. 417).

Interestingly, although members of stigmatized groups, such as race and gender, tend to favour their own group more than other groups, in obesity stigmatization research, overweight and non-overweight children and adults share similar negative perceptions of obesity (Counts, et al., 1986; Kraig \& Keel, 2001; Latner et al., 2005; Tiggemann \& Anesbury, 2000). For example, in a study by Counts et al. (1986), 24 children from third to fifth grade from rural Georgia participated in individual interviews. Children were rated by the two researchers on a 5-point Likert scale on their weight ( $1=$ not fat, $5=$ very fat). The overweight group consisted of twelve children who were matched on grade, gender, and race with a control group (non-overweight). During the interview, children were shown two photographs of an overweight and normal weight individual, of equal height in identical spacesuits and helmets which concealed their faces (Counts et al., 1986). Children were then given a list of positive (e.g being friendlier) and negative characteristics (e.g being more sad) and asked to select which spaceperson embodied that specific characteristic. Results showed that the normal weight spaceperson was associated more often with positive characteristics while the overweight spaceperson was associated more often with negative characteristics (Counts et al., 1986). Results also showed that overweight and non-overweight participants did not differ in their rate of selecting the overweight or normal weight spaceperson for positive or negative characteristics (Counts et al., 1986). However since the study used two research assistants to rate children's weight, these ratings may have been subjective since no standardized measure was used between the two researchers. However regardless of the potential subjectivity of the researchers ratings, other studies have also consistently found no differences between overweight and non-overweight individuals' 
perceptions of overweight figures (Counts et al., 1986; Kraig \& Keel, 2001; Latner et al., 2005; Tiggemann \& Anesbury, 2000).

Researchers have criticized body image literature for ignoring cultural factors that influence body image (e.g., Larkin \& Rice, 2005). Most studies related to body image have mainly focused on Caucasian middle class children and adolescence (e.g., Cramer \& Steinwert, 1998; Dixey, et al., 2001; Greenleaf \& Weiller, 2005; Musher-Eizenmann, Holub, EdwardsLeeper, Person \& Goldstein, 2003). This could affect the data since research has indicated that children from higher social classes are associated with having more negative attitudes towards obesity (Wardle \& Beales, 1986). As well, research has documented that different cultures hold different ideal body images (Grogan, 2008; Larkin \& Rice, 2005). For example, a study conducted by Welch, Gross, Bronner, Dewberry-Moore and Paige (2004) discovered that African-American children chose larger figures to represent their current and ideal body image and also were more satisfied with their body size when compared to Caucasian children. In addition, a study by Skelton, Busey and Havens (2006) found that African-American children between 10 to 19 years of age and their parents underestimated the children's weight. Two thirds of the children who were overweight or at risk of being overweight believed that their weight was normal and healthy (Skelton et al., 2006). Parents also believed that their overweight child's weight was healthy (Skelton et al., 2006). In the 1980s, Latin American, Puerto Rican, Indian, Chinese and the Philippino cultures linked higher body weight with health and wealth (Grogan, 2008). In addition, compared to Caucasian populations, Asian populations were shown to have a greater liking towards overweight individuals (Latner et al., 2005). Therefore, cultural differences may be better understood through continued research exploring the perceptions of individuals from different cultures. 


\section{Theoretical Framework}

Urie Bronfenbrenner's social ecology theory may be used to explain the negative perceptions and stigmatization of overweight individuals in society. Bronfenbrenner's social ecology theory refers to "the entire network of interactions and interdependencies among people, institutions, and cultural constructs to which the developing person must adapt psychologically" (Gray, 2002, p. 455). Bronfenbrenner depicts his theory in a circular diagram where the child is set in the middle and a set of five concentric circles surround the child. The layer closet to the child is his/her immediate environment. Referred to as the Microsystem, it includes people that the child has direct contact with (Gardiner \& Kosmitzki, 2008; Gray, 2002). Parents, peers and teachers of children are within the Microsystem. Greenleaf and Weiller (2005) conducted a study which shows how individuals within the Microsystem can affect children's perceptions. In the study, physical educators completed questionnaires about their perceptions of youth obesity. Results found that physical educators expected normal weight youth to have better overall physical, social interaction, cooperative, and reasoning abilities than overweight youth (Greenleaf \& Weiller, 2005). This is highly alarming since teacher expectations can "influence the quantity and quality of feedback and instruction, and subsequently, student performance" (Greenleaf \& Weiller, 2005, p. 419). Therefore, children who have teachers who have negative views about overweight individuals may come to develop negative perceptions about overweight individuals as well.

The next layer in Bronfenbrenner's social ecology theory is the Mesosytem which is the interrelation among the child's immediate environments. Individuals within the Microsystem do not function independently, but are connected, interrelated, and influence each other (Gardiner \& Kosmitzki, 2008). For example, school and home are two settings in the Microsystem that are 
interrelated. In the following example, prevention programs targeting individuals within a Microsystem versus a Mesosytems will be examined. In a study by Ghaderi, Martensson and Schwan (2005), a prevention program called "Everybody's Different" was implemented in two fifth grade classrooms in order to enhance self-esteem, acceptance, and examine stereotypes which may lead to body dissatisfaction. The program consisted of nine consecutive 50-80 minute weekly in-class lessons in addition to take-home activities. Questionnaires were completed by a treatment and control group prior to and after the program. The results showed that there were no significant improvements in self-esteem, eating attitudes or body image (Ghaderi et al., 2005). According to Bronfenbrenner's model, individuals within the Microsystem do not function independently but are interrelated, therefore perhaps the program was not effective since negative body image or eating attitudes of other individuals within the Microsystem (e.g., parents, peers) may have remained the same. Although the study mentioned take home activities, it is not clear whether these home activities were completed by participants individually, or included parental involvement. Perhaps including parents in activities would create changes in parental attitudes which could ultimately influence children's attitudes. In addition, since "Everybody's Different" consisted only of nine short lessons, perhaps only short-lived changes were made since the school environment may not have changed after the intervention program. Children may benefit more if self-esteem themes are embedded throughout the curriculum which would increase exposure and may make programs more salient. In contrast, another in-school prevention program called Very Important Kids (V.I.K) aimed to minimize weight-based teasing and unhealthy weight-control behaviours targeted towards students in grades four to six (Haines, Neumark-Sztainer, Perry, Hannan \& Levine, 2006). Baseline attitudes and post-program attitudes evaluated eight months after the program were assessed through questionnaires 
completed by students who attended the program and students from a control school. The prevention program incorporated individual (e.g., skills to intervene in weight-teasing situations) and environmental strategies (e.g., school staff training, no-teasing campaign, family-based intervention programs) to reduce teasing. Results of the study indicated that the program effectively reduced the percentage of teasing at the intervention school while there was an increase of teasing in the control school (Haines et al., 2006). Therefore, perhaps the multidimensional program which addressed education targeted both at an individual, environmental, and familial level was effective because both the Microsystem and Mesosytem are included and addressed.

Bronfenbrenner's third layer in his social ecological model is the social context referred to as the Exosystem (Gardiner \& Kosmitzki, 2008). The Exosystem is comprised of external environmental settings that the child may not come into direct contact with but consists of aspects of society that affect the child, such as parents' work places, extended family, hospitals and school boards (Gray, 2002). For instance, Larkin and Rice (2005) showed that school board curriculum can be an important factor for children's body size perceptions. In the study, Larkin and Rice (2005) explored Ontario's Ministry of Education's health curriculum through interviews with seventh and eighth grade girls. The curriculum focused on how to make good food choices and to develop ways to maintain healthy body weight (Larkin \& Rice, 2005). Larkin and Rice (2005) criticized the health curriculum by stating that the program increases awareness of healthy eating, however, children "might read healthy eating messages as an injunction to lose weight" which may create more "pressure to eat the 'right' foods, the 'right' way, to obtain the 'right' shape" (pp. 223-224). Also since healthy living and eating programs at school often focus on what a healthy weight is, children may come to learn that being overweight 
is negative which may increase the likelihood of children who are overweight being stigmatized. Larkin and Rice (2005) also suggest that body weight-harassment is not acknowledged, however, bullying or weight teasing can lead to body image and self-esteem problems. Although the Ontario Ministry of Education is trying to promote healthy living, some of their initiatives may further reinforce that a thin body is ideal and this may affect children's perceptions of overweight children. Therefore, individuals and organizations found within the Exosystem are also important components to the formation of perceptions.

The fourth layer in the social ecological model is the cultural context or Macrosystem (Gardiner \& Kosmitzki, 2008; Gray, 2002). The Macrosystem is "the entire set of beliefs, values, accepted ways of behaving that characterize the historically connected group of people of which the child and his or her family are part of' (Gray, 2002, p.454). Harrison (2000) surveyed students from grade one to three and found that television viewing predicted an increase in eating disorder symptoms and increased males' negative perceptions towards overweight female target figures. This example shows how the mass media can distort children's perceptions of overweight individuals. In addition, in a qualitative study with overweight children, some female participants indicated that their weight restricted the type of clothing they could wear (Wills, Backett-Milburn, Gregory \& Lawton, 2006). Overweight female children in the study stated that they did not enjoy shopping with friends since they were fearful of trying on clothes in front of non-overweight peers (Wills et al., 2006). This suggests that retail chains and other individuals and organizations within the Macrosystem may not cater to the overweight population. Since the number of overweight individuals is increasing, stigma for overweight children may also be created if they cannot wear the latest styles or join their friends in social outings to the mall. The cultural standards and pressures to maintain the ideal body type, which is a thin physique, may 
negatively influence children's perceptions against overweight individuals. A contradiction is created since statistics have shown that global obesity and weight is increasing while the idealization of thinness is the dominant view.

The final outmost layer, the Chronosystem has a temporal dimension (Siegler, Deloache \& Eisenberg, 2003). Children's development is affected by fluctuations of beliefs, values, customs, technologies and social circumstances in society over time (Siegler et al., 2003). In addition, changes in environmental events are also related to chronological variables such as the age of the child (Siegler et al., 2003). Therefore societal changes from valuing overweight bodies to the idealization of thinness over time may have negatively influenced children's perceptions of overweight body types. In addition, as children age and learn to read and write and receive less parental supervision, this increasingly opens up their exposure to the mass media. Since children can now for instance access the internet, read magazines and understand billboards, they are even more exposed to how the media portrays overweight individuals while glorifying and rewarding individuals who are thin.

Bronfenbrenner's social ecological theory clearly explains perceptions of overweight individuals since the many systems and levels of society together create prejudices and promote stigmatization against overweight individuals. This directly relates to the current study since in order to understand how changes should be made in children's social ecological system, research to understand more about children's perceptions and why children have these perceptions will be pivotal in determining what and where changes need to be made in order to decrease weightbased stigmatization. 


\section{Prevention Programs}

To combat weight-based harassment and body esteem issues in children, many researchers have recommended the need to provide universal prevention programs that target a relatively asymptomatic population and emphasizes increasing resilience to body image issues rather than reducing attitudes that already exist (Clark \& Tiggemann, 2007; Smolak, 2004; Smolak \& Levine, 2001). Universal prevention programs may be more beneficial than intervention programs because it may be easier to instill values about respecting others regardless of weight than to eliminate negative attitudes that have already been formed. Therefore, universal prevention programs would seek to target very young children instead of older children, since negative attitudes may not yet have formed in younger children. Studies have identified that stigmatization of children who are overweight increases with age (Cramer \& Steinwert, 1998; Musher-Eizenmann, et al., 2003). In Cramer and Steinwert's (1998) study, preschool children from the ages of three to five were assessed on negative attitudes towards overweight children represented in drawings. Preschool children regardless of age all perceived overweight figures to possess unfavorable characteristics and stigmatization increased as the age of the child increased, with five year olds designating more negative attributes to overweight children than three and four year olds (Cramer \& Steinwert, 1998). In a study by Jarvie (1984), children in third and fifth grade were asked to select between a normal-weight and obese partner for playing a space game. Both the normal-weight and obese figures were wearing identical space suits and helmets while they held onto a card which indicated their competency at playing the game by showing the number of games won and lost previously (Jarvie, 1984). Participants were then asked to select a partner. Findings showed that younger children based their choice on competency while older children made their choices primarily based on body size, choosing 
mainly the normal-weight partner (Jarvie, 1984). Since some studies have indicated that size stigmatization increases with age (e.g., Cramer \& Steinwert, 1998; Jarvie, 1984) it is important for research to uncover when potential body size biases begin in order to address and prevent stigmatization of children based on body size.

Also, in a study by Teachman, Gapinski, Brownell, Rawlins and Jeyaram (2003), two strategies were used to change biases against overweight children. The first strategy used manipulated individuals' beliefs of the causes of obesity. Participants were told that the obesity was either caused by genetic factors or due to behavioral factors. Participants who were told that obesity was caused by behavioural factors had more anti-fat biases. Participants who were told that obesity was caused by genetic factors did not decrease their negative perceptions of obesity. A second strategy was used to evoke empathy towards overweight individuals. This was done by reading participants stories of personal experiences of overweight individuals' experience with prejudice and social rejection. This strategy was effective in reducing biases only in participants who were overweight (Teachman et al., 2003). Teachman et al.'s study highlights that reversing negative perceptions is very difficult therefore providing universal prevention programs may be effective in decreasing body size stigmatization.

In addition, universal prevention programs, such as school-wide programs for all children regardless of age, should target a wider population. Research has documented that the sources of victimization of overweight children are not usually conducted by one specific peer but peers in general (Hayden-Wade et al., 2005). This is an indication that the teasing of overweight children may be acceptable and socially sanctioned by youth culture (Hayden-Wade et al., 2005). Since it would be challenging to identify specific children who stigmatize 
overweight children, it would therefore be more effective to promote school-wide programs to target peer acceptance (Hayden-Wade et al., 2005).

\section{Purpose and Significance of Study}

To date, there has been little research about children's perceptions of body image during the preschool and early elementary years (Cramer \& Steinwert, 1998; Smolak, 2004). Since research has documented that children as young as five years old already possess negative attitudes towards overweight children it will thus be valuable to understand even younger children's perceptions about body image (Birbeck \& Drummond, 2005; Pine, 2001). The principal aim of the study is to examine preschool children's perceptions of overweight children. Age, gender and culture will be examined in order to understand how the variables influence preschool children's perceptions. The findings may be significant in informing curriculum through the development of programs that may prevent or decrease negative body image attitudes and body stigmatization in order to create learning and social environments where all children feel accepted, included and feel that they belong regardless of body shape or size. In order to understand how children's environmental contexts can be influenced to create sustained change towards eliminating weightbased stigmatization, research must discover ways in which children's social ecological system can be influenced to embrace weight differences. In addition, since research has documented that stigmatization may increase with age, understanding more about young children's perceptions would be valuable to understand when children should be exposed to programs that address body image issues and size acceptance (Cramer \& Steinwert, 1998). The current study is an extension of research conducted by Cramer \& Steinwert (1998) with preschool children and Tillman et al.'s (2007) study with elementary school children. The following questions will be examined: 
1) Will preschool children identify overweight children as being 'mean' more often than non-overweight children?

2) Will more negative characteristics be attributed to overweight children as preschool children's age increases?

3) Will male and female children have different perceptions of overweight children?

4) Do cross-gender attributions of overweight children differ from same-gender attributions of overweight children?

5) Are there differences in children's attributions of weight depending on ethnicity?

6) What are children's rationales for identifying a child as being 'mean' or 'nice'? 


\section{Chapter 3: Methods}

This exploratory study examined preschool children's perceptions of others based on weight. Children who participated in the study completed an activity, which included four short stories where in each story, one child acts in a prosocial manner, while the other child behaves in a non-prosocial manner. At the end of each story, children viewed pictures of target figures and answered questions related to their perceptions of the target figures. The Statistical Package for the Social Sciences (SPSS) was used to examine the quantitative data and analysis of themes was used to examine the qualitative data.

Following is a detailed discussion of participants' demographics, procedures used to recruit participants and collect data, as well as a discussion of the materials used. The final section will present a discussion of how validity and reliability were accounted for in the study. Participants

After receiving approval from the Research Ethics Board at Ryerson University, participants were recruited using opportunity sampling. Participants were preschool children between the ages of 32 months to 70 months from early learning and childcare centres (ELCC) across the Greater Toronto Area.

Power calculations indicated that for a Type I error rate of 0.05 a sample size of 34 was more than adequate to obtain a power of 0.80 (based on Tillman's 2003 calculation). Forty-five children received voluntary parental consent to participant in the activity. Two children did not want to participate in the activity because they declined the invitation from the researcher, and one child was on vacation on the day of the activity. The final sample consisted of 42 children, 22 males (Mean age $=48.5$ months $)$ and 20 females (Mean age $=50.3$ months $)$. One male 
participant's data was not considered in the analysis because the child did not understand the procedure or follow the directions of the activity.

\section{Procedures}

The procedures section will discuss the steps involved in participant recruitment and the steps taken prior to the activity with the children in order to increase rapport and comfort for children. Finally, the activity conducted with the children will be explained in detail.

A list of ELCC centres was found through an online search for centres in the Greater Toronto Area. Directors or supervisors (hereinafter, referred to as supervisor) of the centres were contacted by telephone and were informed about the study. During the telephone conversation, the study was explained to the supervisor. Supervisors where then asked if they would be interested in allowing the centre to be a research site for the study. Thirty-four centre supervisors were contacted and eight centre supervisors agreed to allow research to be conducted at their site. Those who agreed to participate in the study received information letters and consent forms to be given to the board of directors or owner/operator. Information letters and consent forms were delivered to the ELCC centres where the supervisor agreed for the centre to be a research site. Supervisors then forwarded the information letter and consent form to their board of directors or owner/operator of the ELCC centres (see Appendix A and B for forms). Centre supervisors were contacted via telephone one week later to see if permission was obtained from the board of directors or owner/operator. If consent was provided by the board of directors or owner/operator, a time was arranged with the supervisor for the researcher to either drop off parent information letters and consent forms to the participating centre and to explain the study to the parents, or to only drop off the information letters and consent forms at the centre to be distributed by the supervisor. Supervisors were asked to estimate how many children between the ages of three to 
five attended their early learning and child care centres. Estimates were used to ensure the appropriate number of information letters and consent forms for each centre. When the board of directors or owners/operators signed consent forms were collected, the parental information letters and consent forms were distributed to the parents or left for distribution by the supervisor.

Eight centres agreed to participate in the study, however, due to summer schedules, a total of five centres participated as research sites. Two centre supervisors allowed the researcher to speak directly to the parents while in three centres the supervisors preferred providing information directly to parents themselves. Supervisors who distributed forms directly to parents were told the study was seeking participants between the ages of three to five, and to therefore only give parents with three to five year old children information letters and consent forms (see Appendix $\mathrm{C}$ for forms). At the time that parental information letters and consent forms were distributed, flyers were given to supervisors to post in the classroom or on the bulletin board in order to serve as a reminder for parents about the study (see Appendix D for flyer).

Parents who gave written consent for their children to participate in the study also completed and returned a brief demographic questionnaire. The questionnaire consisted of three questions asking for the gender and birth date of the child, and ethnicity of both mother and father of the child (see Appendix E for questionnaire). On the consent form, parents were also given the option of allowing or not allowing the activity with their child to be tape recorded. All 42 parents who gave consent for their child to participate in the study also gave consent for the activity to be tape recorded. Parents returned the signed consent form and the questionnaire to the supervisor of the centre, or the child's early childhood educator. The supervisors of the centre were contacted via telephone approximately a week after the initial distribution of consent forms and information letters to inquire about consent form returns. If a few or no forms were returned, 
the supervisor was contacted via telephone periodically to inquire about additional returned consent forms. After supervisors deemed that no more consent forms would be received either because most forms had been returned or parents were given enough time to respond, a date and time was set with the supervisor to go to the preschool classroom to collect the consent forms and conduct the activity with the children. In total, from the five centres, 150 information letters and consent forms were distributed and 45 were returned. Therefore the response rate for this study was $30 \%$.

\section{Data Collection}

Data were collected between the months of June 2008 and July 2008. The first centre was visited on June 23, 2008, at 10:00 a.m. where nine children participated in the activity. The next centre visit was on June $25^{\text {th }}, 2008$ at 3:30 p.m. and three children participated in the activity. The third centre visit was on July $2^{\text {nd }}, 2008$ at 10:00 a.m. and a total of six children were involved in the activity that day. The same centre was visited a second time on July $11^{\text {th }}, 2008$ at 10:30 a.m. since three children who received parental consent were absent on the first day. The fourth centre visited was at 10:00 a.m. on July $10^{\text {th }}, 2008$ and seven children were involved in the activity. The last centre visited was on July $15^{\text {th }}, 2008$ at 10:00 a.m. at which fourteen children participated in the activity. Data were mostly collected in the morning in order to keep data collection times consistent and to account for differences time of day may have on children. However, one preschool classroom was visited in the afternoon since morning activities made conducting the study in the morning inconvenient for the program.

Once in the ELCC centre's classroom, children who received parental consent were introduced to the researcher by the early childhood educator. The researcher invited children who received parental consent to participate in an activity with stories and pictures to help the 
researcher with some homework. All children, except for one, who were invited to participate in the activity, gave verbal consent to participate. Each child participated in the activity individually.

After obtaining children's verbal consent, the researcher asked the child to choose a spot in the classroom or in the playground in order for the child to feel "comfortable and at ease" during the activity (Birbeck \& Drummond, 2005, p. 588). Also by conducting the research in a place familiar to the children it can be "eas[ier] for children to indicate when they have talked enough and want to rejoin their peers" (Dockett \& Perry, 2007, p. 59). Twelve children did the activity in the playground because during the time of the visit, the entire class and the early childhood educators had outdoor time. Outside, children mainly picked a small table or a spot on the ground in the playground to complete the activity. Thirty children participated in the activity in classrooms and also picked a spot to sit on the floor or at an activity table.

Once seated and before beginning the activity, children were told that they could stop the activity at any time and did not have to answer questions they did not want to. This was done in order to "contribute to their wellbeing, through giving respect for their sense of control" (Hill, 2005, p. 68). In addition, before starting the activity, the researcher and the child engaged in a short conversation in order to gain rapport (e.g what did you do in class today?)

After the brief conversation and prior to starting the activity, children were given the following instructions: that he/she would hear four short stories and be shown two pictures for each story. It was explained that they would be asked to identify which figure was the 'mean' child in the story and which figure was the 'nice' child in the story along with some follow up questions (see Appendix F for stories and follow up questions). The researcher also explained to each child that their voices would be recorded. All children verbally consented to participating in 
the activity and having the tape recorder present and turned on. After children gave their verbal consent, the tape recorder was turned on and the activity began.

Each child listened to the four stories (please refer to appendix F for stories). Stories were told in a different order so that stories would be counterbalanced. During each story, the child was shown the accompanying target figures (see Appendix $\mathrm{G}$ for target figures). The target figures were counterbalanced (left side, right side) in order to prevent children from always choosing for example the child on the left as the "mean" child and the child on the right as the 'nice' child. Following each story, children were then asked, "Which of these two boys (girls) is (name of character), the mean one who (action or verbal)? Which of these two boys (girls) is (name of character), the nice one who (action or words said)?" (Cramer \&

Steinwert, 1998, p.432) (see Appendix F for the questions). The two questions were also counterbalanced to ensure that children did not pick the "mean" or "nice" child based on the order of the question. Counterbalancing was all done randomly prior to the interviews, where each child was assigned an order of the stories, appearance of pictures, and question presentation order.

After children matched "mean" and "nice" with a figure, the researcher presented a semistructured standardized open-ended interview in order to understand why the child chose one figure as the 'mean' child and the other figure as the 'nice' child. Although this was not done in Tillman's (2003) and Cramer and Steinwert's (1998) study, open-ended questions were asked in order to obtain more information about children's perceptions of other children based on weight.

In total, the activity lasted an average of four minutes (Minimum $=2.48$ minutes Maximum $=7.08$ minutes). At the completion of the activity, each child was thanked for his/her participation in the study and then returned to his/her normal program activities. 


\section{Materials}

Many body size stigmatization studies have used adjective attribution tasks where children were shown figures, given adjectives (e.g smart, funny, bully) and asked to select which figure possesses the characteristics (Cramer \& Steinwert, 1998). Cramer and Steinwert (1998) questioned whether this task is appropriate for children since "the request to assign abstract personality constructs to pictorial target figures and to make differential ratings of intensity may be too difficult for some young children" (p. 431). Cramer \& Steinwert (1998) argued that the story telling method was more age appropriate. Therefore, for the current study, Tillman's (2003) four stories, pictures and story telling activity were used with permission from the author (see Appendix $\mathrm{G}$ for permission email). The following sections will explain the materials used in detail.

\section{Four Stories}

Tillman's (2003) stories are very short, consisting of a few sentences each (see Appendix F for stories). Two of the short stories depict male children and two of the short stories depict female children. In addition, for each gender, one realistic story and one fantasy story were created. Realistic stories were created in order to "elicit the children's attitudes about people they might actually encounter" while the fantasy story was created for the purpose of "reduc[ing] the likelihood that children were responding on the basis of a personal past experience, rather than on the basis of a generalized stereotype" (Cramer \& Steinwert, 1998, p. 432). Each story is about two same gendered characters. One character does or says something 'nice' while the other character does or says something 'mean'. Heyman \& Gelman (1999) have indicated that children "may use the term 'nice' as an indication of their positive feelings about someone rather than as a description of what that person is generally like (p. 605). Therefore using the terms 'nice' and 
'mean' was appropriate since “young children's trait assignments may be based on overall evaluations of a character's likeability" (Tillman et al., 2007, p. 71).

\section{Target Figures}

For each story, two same-gendered target figures are used, with one figure being overweight and the other figure being non-overweight. Figures are black and white line drawings of non-specific ethnicity. In total, eight figures are used (see Appendix $G$ for target figures). To control for confounding factors, Tillman's (2003) two target figures for each story are identical in height, clothing, and hairstyle; the only difference is weight and face (Cramer \& Steinwert, 1998). Research has indicated that facial attractiveness could potentially be a confounding factor when measuring for body size (Jarvie et al., 1983). Although Tillman's (2003) target figures for each story had identical facial features, facial chubbiness indicators were drawn under the eyes and chin of the overweight target figures, therefore making the two faces look slightly different. Therefore, slight alterations were made to Tillman's figures with the faces of all target figures replaced with blank ovals based on Jarvie et al.'s (1983) recommendations since one face may have been interpreted as more attractive than the other. Also, figures are computer drawn to avoid any confounding factors that hand drawn figures may have created (Tillman, 2003). Since the only difference between the two figures in the current study is body size, the child's identification of 'nice' and 'mean' is based solely on body size (Cramer \& Steinwert, 1998). Validity and Reliability

To avoid confounding differences between figure sets and to increase validity, for each story, each child was presented with the same figure set for that story (Tillman, 2003). Order of stories presented was counterbalanced across participants and the positions of the "nonoverweight' and 'overweight' figures were counterbalanced between stories (Cramer \& 
Steinwert, 1998). This step was taken to ensure that participants did not have a pattern of always associating, for example, the figure on the left as 'mean' and the figure on the right as 'nice'. In addition, there was an alternation of the presentation of the mean/nice question (Cramer \& Steinwert, 1998). This was done in order to ensure that selections did not have to do with the order that questions were presented in.

For qualitative data, validity was ensured through member checks. Throughout the activity, the researcher tried to make accurate interpretations of the child's answers by often repeating the child's answer and waiting for them to say yes, in order to account for validity through member checking (Creswell, 2008). 


\section{Chapter 4: Results}

The purpose of the study was to explore preschool children's perceptions of other children based on weight. The following section will discuss the findings of the study. The study consisted of participants hearing four short stories, two about boys and two about girls, where one child in the story says or does something 'nice' and the other child does or says something 'mean'. After each story, children were shown two target figures who were identical except for weight. One target figure was overweight while the other target figure was non-overweight. Children were asked to select which figure was the 'mean' child in the story, and which figure was the 'nice' child in the story. Children were then asked to explain why they made the decision they did. Participants were 41 preschool children between 32 to 70 months of age.

Results will be presented based on the research questions. The questions include the number of times overweight target figures are chosen as 'mean' compared to 'nice' and if choices differ depending on age, gender and ethnicity of children. These questions were examined using SPSS. Lastly, children's rationales for identifying a target figure as being 'mean' or 'nice' were analyzed using emerging themes in order to gain a further understanding about children's perceptions about weight.

Research Findings

\section{Question 1: Children's Perceptions of Weight}

The first research question sought to examine if preschool children identified overweight children as being 'mean' more often than 'nice'. Overweight target figures were assigned a code $(0=$ nice, $1=$ mean $)$. A higher score would indicate children chose overweight target figures as being 'mean' more often. 
To examine if preschool children perceived overweight target figures as mean more often than nice, frequencies were calculated. Each participant heard four stories; therefore, each participant could rate the overweight child as 'mean' for no stories, some stories or all stories. Table 1 shows the frequencies and percentages for how the overweight target figure was perceived. The results indicate that $43.9 \%$ of children perceived the overweight target figure to be 'mean' in all four stories, while only $2.4 \%$ of children perceived the overweight target figure to be 'nice' in all four stories.

Table 1

Frequencies and Percentages of Overweight Target Figure Categorized as 'Mean'

Number of Stories where Overweight Target Figure was

\begin{tabular}{ccc} 
Labeled as 'Mean' & Frequency & Percentage \\
\hline 0 & 1 & 2.44 \\
1 & 4 & 9.76 \\
2 & 8 & 19.51 \\
3 & 10 & 24.49 \\
4 & 18 & 43.90 \\
\hline
\end{tabular}

To determine if there was a statistically significant difference between the number of times children labeled overweight target figures as 'mean' or 'nice', chi square tests were completed for each story individually, and then for all four stories combined.

$$
\text { Story } 1 \text { - Male Fantasy Story }
$$

A one-sample chi-square test was conducted to assess whether overweight target figures in story one were rated as 'mean' or 'nice' more often. The results of the test were significant, $\chi^{2}$ 
$(1, N=41)=5.49, p=.02$. The proportion of children who rated the overweight target figure as 'mean' $(P=0.68)$ indicates that more children labeled the overweight target figure as 'mean' ( $M$ $=0.68)$ than 'nice' $(M=0.31)$.

\section{Story 2 - Male Realistic Story}

A one-sample chi-square test was conducted to assess whether overweight target figures in story two were rated as 'mean' or 'nice' more often. The results of the test were significant, $\chi^{2}$ $(1, N=41)=7.05, p=.01$. The proportion of children who rated the overweight target figure as 'mean' ( $P=0.71)$ suggests that more children labeled the overweight target figure as 'mean' ( $M$ $=0.71)$ than 'nice' $(M=0.29)$.

\section{Story 3 - Female Fantasy Story}

A one-sample chi-square test was conducted to assess whether overweight target figures in story three were rated as 'mean' or 'nice' more often. The results of the test were significant, $\chi^{2}(1, N=41)=10.76, p=.001$. The proportion of children who rated the overweight target figure as 'mean' $(P=0.76)$ indicates that more children labeled the overweight target figure as 'mean' $(M=0.76)$ than 'nice' $(M=0.24)$.

\section{Story 4 - Female Realistic Story}

A one-sample chi-square test was conducted to assess whether overweight target figures in story four were rated as 'mean' or 'nice' more often. The results of the test were significant, $\chi^{2}$ $(1, N=41)=17.78, p<.001$. The proportion of children who rated the overweight target figure as 'mean' $(P=0.83)$ highlights that more children labeled the overweight target figure as 'mean' $(M=0.83)$ than 'nice' $(M=0.17)$. 


\section{Overall Story Effect}

A one-sample chi-square test was conducted to assess whether overweight target figures in all four stories were rated as 'mean' or 'nice' more often. Since four stories were told, each story where participants rated the overweight child as 'mean' was assigned a score of 0.25 . If a child indicated that the overweight child was 'mean' in all four stories, a score of 1.0 was assigned. Each story was given a proportion of 0.25 in order for the chi-square test to recognize that the sample size is 41 . If each story was given a score of 1.0 , then it would seem as if 164 participants were involved instead of 41 , since each story was told 4 times.

The results of the test were significant, $\chi^{2}(4, N=41)=20.59, p<.001$. The proportion of children who rated the overweight target figure as 'mean' $(P=0.75)$ shows that more children labeled the overweight target figure as 'mean' than 'nice'. Therefore children perceived overweight children as 'mean' more than 'nice'.

\section{Question 2: Children's Perceptions of Weight by Age}

The second research question examined if more negative perceptions of overweight target figures will emerge as age of children increases. Children's ages ranged between 32 months and 70 months $($ Mean age $=50.25$ months $)$. Children were categorized in three groups based on age ( $1=32-47$ months; $2=48-59$ months; $3=60-70$ months $)$.

A one-way analysis of variance (ANOVA) was conducted to determine if there was a difference between the independent variable, age (32-47; 48-59; 60-70 months) and the number of times that participants rated the overweight child as 'mean' or 'nice' in all stories overall. The dependent variable was the number of times that children chose the overweight child as 'mean' or 'nice'. The ANOVA was not significant, $F(2,38)=1.31, p=.28$. The strength of the relationship between the overweight target being picked as 'mean' or 'nice' in relation to age, as 
assessed by $\eta^{2}$, was weak, with the age factor accounting for $7 \%$ of the variance of the dependent variable. Although there were no significant differences between age groups, the results showed that as age increases, negative perceptions of overweight children increase. Table 2 presents the averages of overweight target figures being labeled as 'mean' by age.

Table 2.

Overweight Target Figure Labeled as 'Mean' by Age

\begin{tabular}{cccc}
\hline Age & M & SD & N \\
\hline $32-47$ & 0.68 & 0.28 & 19 \\
$48-59$ & 0.75 & 0.31 & 14 \\
$60-70$ & 0.88 & 0.19 & 8 \\
\hline
\end{tabular}

Question 3: Children's Perception of Weight by Gender

The next question was to examine if male and female children had different perceptions of overweight children. The independent variable gender includes two levels: male and female. The dependent variable is the number of times that children chose the overweight child as 'mean' or 'nice'. The results were analyzed by story using ANOVA for each story. No significant gender differences were found for story one $F(1,39)=1.22, p=.28$, story two $F(1,39)$ $=0.01, p=.92$, story three $F(1,39)=0.64, p=.45$, or story four $F(1,39)=1.36, p=.25$. A oneway analysis of variance was conducted to determine if there was a difference between the number of times that male and female participants rated the overweight child as 'mean' or 'nice' all four stories. The ANOVA was not significant, $F(1,39)=0.17, p=.68$. Therefore the results show that there is no significant difference between male and female children's perceptions of overweight children. 


\section{Question 4: Cross-Gender Attributions}

To determine if cross-gender attributions of weight differed from same-gender attributions of weight, chi-square tests were conducted for male and female separately for each story. That is, do male participants had more negative perceptions of females overweight target figure than males overweight target figures, or do female participants had more negative perceptions of male overweight target figures than female overweight target figures.

\section{Story 1 - Male Fantasy Story}

A one-sample chi-square test was conducted to assess whether females rated the overweight male target figures in story one as 'mean' or 'nice' more often. The results of the test were not significant, $\chi^{2}(1, N=20)=0.80, p=.37$. Female children did not rate the overweight male target figure as 'mean' $(P=0.60)$ more often than they rated the overweight male target as 'nice'. To determine if cross-gender attributions were different than same-gender attributions, a one-sample chi-square test was conducted to assess whether males rated the male overweight target figure in story one more often as 'mean' or 'nice'. The results of the test were significant, $\chi^{2}(1, N=21)=5.76, p=.02$. Male children rated the overweight male target figure 'mean' $(P=$ 0.77) more often than they would rate the overweight male target figure as 'nice'. Therefore, this indicates that male children rated the male fantasy overweight target figure as 'mean' more often than female children.

\section{Story 2 - Male Realistic Story}

A one-sample chi-square test was conducted to assess whether females rated the overweight male target figures in story two as 'mean' or 'nice' more often. The results of the test were not significant, $\chi^{2}(1, N=20)=3.20, p=.07$. Female children did not rate the overweight male target figure as 'mean' $(P=0.70)$ more often than they rated the overweight male target as 
'nice'. To determine if cross-gender attributions were different than same-gender attributions, a one-sample chi-square test was conducted to assess whether males rated the male overweight target figure in story two more often as 'mean' or 'nice'. The results of the test were significant, $\chi^{2}(1, N=21)=3.86, p=.05$. Male children rated the overweight male target figure 'mean' $(P=$ 0.71) more often than they would rate the overweight male target figure as 'nice'. Therefore, this indicates that male children labeled the male realistic overweight target figure as 'mean' more often than female children.

\section{Story 3 - Female Fantasy Story}

A one-sample chi-square test was conducted to assess whether males rated the female overweight target figure in story three more often as 'mean' or 'nice'. The results of the test were significant, $\chi^{2}(1, N=21)=8.05, p=.01$. Male children rated the overweight female target figure 'mean' $(P=0.81)$ more often than they would rate the overweight female target figure as 'nice'. To determine if cross-gender attributions were different than same-gender attributions, a onesample chi-square test was conducted to assess whether females rated the overweight female target figure in story three as 'mean' or 'nice' more often. The results of the test were not significant, $\chi^{2}(1, N=20)=3.20, p=.07$. Female children did not rate the overweight female target figure as 'mean' $(P=0.70)$ significantly more often than they rated the overweight female target as 'nice'. Therefore, this indicates that male children labeled the female fantasy overweight target figure as 'mean' more often than female children.

\section{Story 4 - Female Realistic Story}

A one-sample chi-square test was conducted to assess whether males rated the female overweight target figure in story four more often as 'mean' or 'nice'. The results of the test were significant, $\chi^{2}(1, N=21)=5.76, p=.02$. Male children rated the overweight female target figure 
'mean' $(P=0.76)$ more often than they rated the overweight female target figure as 'nice'. To determine if cross-gender attributions were different than same-gender attributions, a one-sample chi-square test was conducted to assess whether females rated the overweight female target figures in story four as 'mean' or 'nice' more often. The results of the test were significant, $\chi^{2}(1$, $N=20)=12.80, p<.001$. Female children rated the overweight female target figure as 'mean' $(P=0.90)$ more often than they rated the overweight female target as 'nice'. Therefore, this indicates that female children labeled the female realistic overweight target figure as 'mean' more often than male children.

Overall, the results from all four stories indicate that male children were more negative towards overweight male and female target figures than female participants in three stories. However, female participants were more negative towards female overweight target figures than male participants in one story. Therefore, in three out of four stories, children rated overweight target figures of the same gender as 'mean' more often than they rated overweight target figures of the opposite gender as 'mean'.

\section{Question 5 - Children's Perception of Weight by Ethnicity}

In order to understand if children's perceptions of weight were dependent on ethnicity, children's ethnicities were reported by parents. A total of 22 ethnicities were reported by parents on the returned demographic questionnaire. Among the 22 ethnicities, 13 children had mothers and fathers who listed different ethnic backgrounds. In addition, 8 parents also indicated that they had two or more ethnicities (e.g., Irish-German). Therefore, some children in the sample were multi-ethnic, making the total number of ethnicities even greater than 22. Given the high number of ethnicities and moderate sized sample, ethnicity was not considered further in the analysis. Therefore this study was not able to explore if children's perceptions of weight were 
dependent on children's ethnicities. Table 3 shows the wide cultural diversity of the participants from the study.

Table 3.

List of Reported Ethnicities

\begin{tabular}{|c|c|c|}
\hline & Mother & Father \\
\hline & $\mathrm{N}$ & $\mathrm{N}$ \\
\hline Anglo-Irish & 1 & 1 \\
\hline Anglo-Norweigian & 1 & 0 \\
\hline British & 1 & 0 \\
\hline Canadian & 18 & 15 \\
\hline Chinese & 7 & 7 \\
\hline Croatian & 1 & 0 \\
\hline Czech & 1 & 0 \\
\hline Dutch & 1 & 0 \\
\hline Dutch-Irish & 0 & 1 \\
\hline East-Indian & 1 & 1 \\
\hline English & 1 & 0 \\
\hline Filipino & 1 & 1 \\
\hline French & 1 & 2 \\
\hline Irish-German & 1 & 0 \\
\hline Italian & 1 & 3 \\
\hline Jewish & 0 & 1 \\
\hline Korean & 0 & 1 \\
\hline Scottish & 0 & 2 \\
\hline Serbian & 1 & 2 \\
\hline South African & 1 & 1 \\
\hline Turkish & 1 & 1 \\
\hline Zimbabwe & 0 & 1 \\
\hline
\end{tabular}

Note: Ethnicities reported as were seen on demographic questionnaire 


\section{Question 6: Children's Rationales}

To understand children's rationales for identifying a child as being 'mean' or 'nice', children's responses were coded and analyzed using emerging themes. Of the 41 children who participated in the activity, 31 children gave a rationale for choosing their target figure. The qualitative findings will be discussed using the narratives of children to describe and explain themes that emerged through children's answers.

The data were initially coded based on emerging themes which were children's recognition of the differences of height, body size and body parts between overweight and nonoverweight target figures. For example, emerging themes included emotional attributes, personality, level of bravery, bullying, eating habits and clothing. Children also used reasoning of the story to explain why one child was the 'mean' child, some children indicated that they did not know why they picked one figure as 'mean' or 'nice' and some children did not answer the question.

Through the emerging themes, three bigger themes were created: 1) perceptions of physical attributes of overweight children, 2) perceptions of emotional attributes of overweight children and 3) perceptions of behavioural attributes of overweight children. This was created by grouping the emerging themes into specific categories. Since children's justifications consisted of reasons based on physical (i.e., size, height, body parts, eating, clothing), emotional (i.e., angry, happy), and behavioural attributes (i.e., bullying, personality, bravery), these three categories were created. Finally the section will describe children using the character's action in the story as their rationale for their choice as well as children indicating that did not know and children who did not provide a response to the question. 


\section{Perceptions of Physical Attributes of Overweight Children}

The majority of responses by children about the overweight target figure were directed towards the target figure's physical attributes such as size, clothing attire, body proportions, and height. These physical attributes were used by the children to justify their opinions of the overweight target figure.

Eleven out of the thirty-one children who gave rationales indicated that the overweight child was the 'mean' child because of size. Comments such as, "the bigger one is mean and the littler one is nice", “'cause she's fat" or "because he looks more bigger" were used. Therefore, $35 \%$ of children who gave responses used body size as a justification for rating overweight target figure as the 'mean' child.

In addition to body size, children also indicated specific body parts which made the overweight child the 'mean' child. The following is a rationale given by a boy who is 51 months of age.

Researcher: Can you tell me why you chose this child as the mean child? (points to overweight figure)

Bobbie*: Umm I don't quite know.

Researcher: Is there something about these two that makes this one look meaner?

Bobbie: $\quad$ The middle (points to stomach area)

The same child also suggested that "the middle" can also make someone look nicer.

Researcher: Can you tell me why you chose this child as the nice child? (points to overweight figure)

Bobbie: 'Cause he looks nice!

Researcher: 'Cause you think he looks nice? Why do you think he looks nice?

Bobbie: (points to the stomach area)

Researcher: Again this middle part?

Bobbie: Yeah.

Similarly, the overweight target figures' stomach area was pointed out to be negative in another conversation where a 53 month old boy indicated that bigger people are meaner "because they

\footnotetext{
${ }^{*}$ All children's names mentioned in the study are not their real names in order for children to remain anonymous.
} 
have a fatter belly, they eat more" and the 'nice' one "has a skinnier belly. Because they don't eat as much as the fat belly." Other body part related justifications for an overweight child being mean included "because he has shorter arms" whereas the non-overweight child was nicer "because he has longer arms." Although shorter arms may not be a negative physical characteristic, children turned it into a dichotomy where one physical features (longer arms) was better than another physical feature (shorter arms) and this feature defined if someone was 'nice' or 'mean'.

Height was also a factor for perception of being 'mean' or 'nice'. One child indicated that they chose the non-overweight child as the nice child because "she's taller" but the mean child was mean because "she's fat". Clothing was also used as a justification for choosing one child as the 'mean' child. Although both target figures wore identical clothes, children pointed out that the overweight target figures clothing was bigger, making them meaner. For instance, children responded that overweight children were chosen as 'mean' because "it's [the dress] really big". A boy 44 months of age illustrates how clothing is used as a rationale for overweight children being labeled as 'mean'.

Researcher: Why did you choose this child as the 'mean' child? (points to overweight figure) Jimmy: Because she has a bigger dress Researcher: Because she has a bigger dress? And do you think people who wear bigger dresses are meaner?

Jimmy: Uhh...yeah

Researcher: And why do you think they're meaner?

Jimmy: Because that's why they're mean.

In response to the male fantasy story, the same child indicates that he chose the overweight child as the 'mean' child:

Jimmy: Because he has bigger shorts

Researcher: Okay. And why do bigger shorts make him meaner?

Jimmy: I think because they're wearing bigger shorts. 
A 61 month old female child also notes clothing as a reason for labeling the overweight child as being 'mean'

Jennifer: 'Cause it doesn't, 'cause ummm like it doesn't have a nice dress, and and like she she she ummm she didn't let her go on, cuz she was really mean and she didn't want to be nice to her.

Researcher: Really mean? Okay... and why do you think the dress makes her meaner?

Jennifer: $\quad$ Because, 'cause it's really big and she really looks mad

By suggesting that bigger clothing is a reason for being mean, and bigger children wear bigger

clothing, this ultimately leads to the idea that being physically overweight is a negative attribute.

In summary, 17 out of 31 children who gave rationales used physical attributes and clothing to

justify why they believed that overweight target figures are 'mean'. Therefore, children's

rationales suggest that overweight children are stigmatized due to their physical size already at a young age.

\section{Perceptions of Overweight Children's Behavioural Attributes}

Behavioural attributes were also used to rationalize why children choose overweight figures as 'mean'. In the following example, a 68 month old female explained that overweight children were mean because they treated other people negatively.

Researcher: Can you tell my why you chose this child as the 'mean child? (points to overweight child)

Laura: $\quad$ Because he's fat.

Researcher: Because he's fat? Umm okay, and do you think fatter people are usually meaner? Laura: (nods)

Researcher: Yeah? Okay, and is it because someone bigger has been meaner to you before? Laura: (nods)

Researcher: Okay? So what happened?

Laura: $\quad$ A boy is mean, and he called me deaf but I wasn't.

In the next example, a 53 month old boy describes overweight children as villains who fight "good guys".

Researcher: Why did you choose this child as the 'mean' child? (points to overweight child) Gabriel: $\quad$ Cuz he's fatter! 
Researcher: Okay, and do you think fatter people are meaner?

Gabriel: Yeah!

Researcher: Why do you think bigger people are meaner?

Gabriel: $\quad$ Because they have a fatter belly, they eat more.

Researcher: They eat more? So are people who eat more meaner?

Gabriel: $\quad$ Yeah.

Researcher: Why do you think so?

Gabriel: Because then they're stronger.

Researcher: And why are stronger people meaner?

Gabriel: $\quad$ To fight good guys.

This boy not only has a negative perception of overweight children's behaviours and

relationships with others, but he seems to be attributing being overweight with the amount of food eaten.

Another attribute that emerged from the dialogue was the perception that overweight children are selfish. After a 61 month old female child was told the female reality story about the 'mean' child not returning a red bouncy ball that was lent to her, the child indicated that "she looks really really mean (referring to overweight figure) and doesn't (child pauses) doesn't want to give it back and doesn't want to be nice". Further along in the dialogue, the child continues to explain that, "[the overweight figure] likes the ball and wants the ball and keep it all for herself".

Therefore preschool children in the sample had negative perceptions about how overweight children would behave in social situations and interact with other children.

\section{Perceptions of Emotional Attributes of Overweight Children}

Throughout the interviews, many children indicated that the overweight child looked 'angry' or 'mad'. This is an interesting finding since there are no facial features for the target figures. Children thus used body weight as a cue to predict if someone was a 'happy' or 'angry' person. For example, a child indicated that "they (overweight vs. non-overweight target figure) have a different face, and her face (referring to overweight figure) looks a little bit mad." Other examples include children being asked why they chose the overweight figure as the 'mean' child 
and responses include "because she's mad" or "because he's mad at him!" Children often associated the overweight figure as being 'mad' while the non-overweight figure was usually labeled as 'happy". Being mad is related with being mean, while being happy is related to being nice.

The next illustration also demonstrates that children perceive overweight individuals to possess negative emotions. In this instance, a 61 month old female child announces that overweight children say negative things about others.

Researcher: Why did you choose this child as the 'nice' child? (points to non-overweight figure)

Jennifer: $\quad$ Cuz ummm it's, it looks a little bit happy (points to non-overweight) and this one looks mad (points to overweight), and this guy (points to overweight) looks a little bit too fat, and this guy doesn't look fat (points to non-overweight)

Researcher: Okay so one is fat and one is not fat. And why do you think the fat one is meaner in this story?

Jennifer: Because this guy (points to overweight) looks a little bit jealous, and this one looks a little bit nice (points to non-overweight).

Researcher: So do you think bigger people are jealous?

Jennifer: Yeah

Researcher: Yeah? Okay. And why are they jealous, what are they jealous about?

Jennifer: Because sometimes they say things that are not nice.

The child believes that overweight children are jealous of non-overweight children and this often drives overweight children to say negative things. This may suggest that this child believes that overweight children are jealous of non-overweight children because she believes that it is better to be non-overweight.

Interestingly, a 54 month old boy chose the overweight child as the 'nice' child and his rationale was that:

Leon: Because this one is thinner and that one is fatter. Because that one (refers to non-overweight figure) says, you're fat!

Researcher: So the bigger one is nicer?

Leon: Because he's fat. And he (referring to non-overweight figure) said he didn't want to be partners "'cause you're fat!" 
This case has shown that even young children may be aware of overweight children being stigmatized or teased by their peers.

Through the dialogue with children, children have shown that they assume overweight children are 'mean' because they are angry, mad, and sometimes jealous of non-overweight children. In addition, overweight children may suffer from stigmatization from their peers.

\section{Other Responses}

Thirteen out of thirty-one children used the character's action in the story as their rationale for why one child was the 'nice' child and the other was the 'mean' child. Below is an example from a 70 month male child's answer.

Researcher: Amy and Laura went outside to the playground. Amy was very kind and let Laura use her favorite red bouncy ball. At the end of the outdoor time, Amy said, "Could I have my ball back?" Laura said, "No" and dropped the ball into a puddle of mud.

Nigel: $\quad$ (Picks overweight child as the mean child)

Researcher: Why did you choose this child as the 'mean' child? (referring to overweight child) Nigel: $\quad$ Because she's took the ball and she threw it in the mud

Additionally, 11 out of 42 children indicated that they did not know why they chose one child as 'nice' and the other as 'mean' or did not respond to the question.

In summary, 31 out of 42 children provided responses to explain why they chose one child as 'nice' and the other as 'mean'. The themes consisted of perceptions of overweight children's physical appearance, behavioural and emotional attributes. Children's rationales highlight that even preschool children perceived overweight children to have negative characteristics.

Review of the General Findings

The findings indicated that children labeled overweight target figures as 'mean' more often than 'nice' while non-overweight target figures are labeled as 'nice' more often than 
'mean'. Age and gender are not associated with children's perceptions of weight however results show that children were more likely to perceive overweight children of the same gender more negatively than overweight children of the opposite gender. Finally, children were shown to perceive overweight children negatively due to physical, behavioural, and emotional attributes. 


\section{Chapter 5: Discussion}

The purpose of this study was to examine preschool children's perceptions of overweight children. The findings of the study will be discussed in the following section. Based on the results, children's perceptions of weight will be discussed. Using Bronfenbrenner's social ecological model as a theoretical framework, the results of the study will be used to make recommendations on ways to decrease weight-based stigmatization amongst children. Finally, limitations of the study, suggestions for future studies and the study's contributions will be outlined.

\section{Children's Perceptions of Weight}

The first research question was to examine if preschool children would label overweight target figures as 'mean' more often than 'nice'. The findings suggested that for all four stories, children rated the overweight target figure as 'mean' more often than 'nice'. This finding showed that among preschool children, obesity was highly stigmatized. Results were consistent with the Cramer and Steinwert (1998) and Tillman (2003) studies which found that overweight target figures were labeled 'mean' more often than 'nice'. This result is also consistent with many previous studies which have shown that children have shown more negative associations towards overweight figures than non-overweight figures (e.g., Birbeck \& Drummond, 2005; Cramer \& Steinwert, 1998; Counts et al., 1986; Kraig \& Keel, 2001; Latner, Stunkard \& Wilson, 2005; Lerner \& Kron, 1972; Pine, 2001; Tiggemann \& Anesbury, 2000; Staffieri, 1967; Tillman et al., 2007; Turbull et al., 2000). This result is highly alarming since the prevalence of overweight children is on the rise, therefore, more overweight children may be stigmatized and face the negative psychological and emotional consequences of weight-based bias. The result highlights that preschool-aged children have already formed negative perceptions of children who are 
overweight. This is a significant finding since few studies have looked at very young children's perceptions of weight. Since children as young as two-and-a-half years old have formed negative perceptions of weight, research must continue to explore when these perceptions first begin to form. It will be imperative to explore the origins of weight-based stigmatization in order to understand when and where prevention programs to decrease weight bias should be provided to children.

\section{Children's Perceptions of Weight by Age}

The second research question was to understand if stigmatization of overweight target figures increased with age. The results of the study found no significant difference between perceptions of participants 32-47 months, $48-59$ months, or 60-70 months. Children regardless of age rated the overweight target figure as 'mean' more often. This result is consistent with a study by Tiggemann \& Anesbury (1997) who found that participants between the ages of 8 to 12 had negative stereotyping of overweight children which were uniform regardless of the child's age. Latner, Simmonds, Rosewall and Stunkard (2007) asked children between the ages of 10-13 to rank their preferences of figures of children who either had no disabilities, various disabilities or who were overweight. The findings found no difference between children's preferential ranking due to age which is consistent with the current findings (Latner, Simmonds, Rosewall \& Stunkard, 2007). Although some studies have been consistent with the results of this study, how age is associated with weight stigmatization has often been conflicting. For example, Cramer and Steinwert (1998) found that preschool participant's weight-stigmatization became more negative as age increased. On the contrary, a study by Powlishta, Serbin, Doyle and White (1994) found that in a sample of children from kindergarten to grade six, attitudes towards obesity became more flexible with age with older children becoming less negatively biased. 
Although no differences between age groups were found in this study, this may have been due to the sample size. However, averages scores were in the direction of stigmatization increasing with age. According to social learning theory, children learn primarily through observation and imitation (Siegler, Deloache \& Eisenberg, 2003). Therefore, children learn, for example, from observing other people interact or from watching television. As children age and become more exposed to the media or become more aware of cultural perceptions, it is possible that negative attitudes will gradually increase over time throughout childhood. Therefore, since overweight individuals are negatively stereotyped in popular culture and society, children's perceptions of overweight individuals may continue to increase throughout childhood.

Future studies need to continue to explore how age is related to perceptions of overweight individuals. Perhaps a larger sample size including various ranges of age will help clarify how age and development is correlated with stigmatization of overweight individuals. In addition, since children as young as two-and-a-half years old in the current study were seen to have negative perceptions of overweight children, it raises the question of when these negative perceptions begin. Research has shown that infants 2 to 6 months of age already prefer attractive faces compared to less attractive faces (Lagnlois, Ritter, Roggman, \& Waughn, 1991 as cited in Siegler et al., 2003). Therefore, it would be interesting to explore if negative perceptions towards overweight individuals is inherent in children or if stigmatization develops throughout life. By understanding when weight-based biases originate, programs created to either prevent or attempt to eliminate these negative attitudes can be more effectively developed.

\section{Children's Perceptions of Weight by Gender}

The third research question was to understand if male and female children had different perceptions of other children based on weight. The findings showed no significant differences 
between how male or female participants rated the overweight target figure. Children of both genders rated overweight target figures as 'mean' more often than 'nice'. This finding is consistent with studies that have found that children of both genders perceived overweight target pictures negatively (e.g., Cramer \& Steinwert, 2003; Tillman et al., 2007).

The next question was to understand if children were more negative towards the overweight figures of the opposite gender. Findings showed that in three out of four stories (male fantasy, male realistic, and female realistic), children rated overweight children of the same gender as 'mean' more often than overweight children of the opposite gender. Therefore, the results indicate that children are more negative towards overweight children of the same-gender. Developmental theory may explain this result. Preschool children begin gender segregated play and this tendency peaks around the ages of eight to eleven and then declines slowly (Siegler, Deloache \& Eisenberg, 2003). Since children engage in same-gender play more often, perhaps overweight children of the same gender are perceived more negatively by peers of their own gender because they may not conform to gender schemas. For example, traditional sex-role stereotypes emphasize that boys should be capable of playing sports. Therefore, an overweight boy may be less skilled at playing sports or play at a slower speed due to physical constraints, hence be liked less by non-overweight male peers. Due to gender-segregated play, females at this age interact less with overweight males and place more value on social relationships and not sports, therefore, an overweight male that may have physical disadvantages playing sports may not negatively affect females. Thus, same-gender stigmatization may be higher amongst preschool children since gender-segregated play is more common and overweight children of the same-gender may be seen as different and therefore negatively perceived amongst their same-sex peer group. 
Interestingly, results also showed that male participants labeled overweight target figures as 'mean' more often than female participants. Consistent with these results is a study conducted by Latner et al. (2005) who found that males liked overweight peers less than females did. However, it should be noted that Latner et al.'s (2005) study was conducted with college students and therefore may not be directly compared to the current study. Also, another study with children from kindergarten to grade six has shown that when attributing positive traits to overweight and non-overweight individuals, male participants were more negative to overweight individuals than female participants (Powlistha, Serbin, Doyle \& White, 1994). This may show that males in general, are more disapproving of overweight individuals. In contrast, other studies have shown that female children are more negative towards overweight children than male children (Latner \& Stunkard, 2002). Researchers have speculated that females would be more negative towards overweight individuals since more emphasis is placed on appearance that would affect social relationships while males are more negative towards individuals with limitations to their physical ability (Richardson et al., 1961). However, since being overweight may also affect physical ability, males may also have high negative perceptions of overweight individuals. Alternatively, a study showed that many explicit measures looking at weight bias did not reveal biases that women held towards overweight individuals that were seen through implicit measures (Schwatz, Chambliss, Brownell, Blair \& Billington, 2002). Since society teaches boys and girls to behave in gender-appropriate ways, such as stressing assertiveness in males, males perhaps are more likely to speak their minds while females have learned to be agreeable and nice, and therefore may not wish to offend others explicitly, although they may have negative perceptions of overweight individuals. This may explain why in the current study, males were more negative towards overweight target figures than female children. 
This study also found that male and female children rated the overweight female figures as 'mean' more often than they rated the overweight male figures as 'mean'. Pine (2001) found that in a study with children between the ages of five to eleven, children labeled the nonoverweight female figures to have more feminine traits than overweight female figures, however, masculine traits were not associated with only the overweight or non-overweight male. In other words, females must be thin to be viewed as feminine, but males can be seen as masculine regardless of size. Possibly, children in this study also demonstrated this bias by viewing overweight female figures as more negative than overweight male figures. This would explain why male and female children rated the overweight male figures as 'mean' less often than female overweight figures since less stigma may be associated with overweight males.

Noteworthy to mention, in the female realistic story, female children rated the overweight figure as 'mean' more often than male children. This was the only story where female children rated the female overweight figure as 'mean' more often than male children. Perhaps female children did not label overweight male figures as 'mean' as often as males because society generally places greater negative stigmatization on overweight females than on overweight males. Female children may also not have rated the overweight female figure as 'mean' more often than nice in the fantasy story since the story was viewed as not likely to happen in real life. The fantasy stories were created to elicit children's generalized stereotypes while realistic stories were created to understand children's attitudes of people with whom they may actually come into contact. Therefore, female preschool children perhaps have less negative generalized stereotypes towards overweight children than male preschool children, and only rated the overweight realistic female as 'mean' more often than the non-overweight realistic female character based on past experiences. 
More research needs to be conducted in order to understand how gender is related to children's perceptions. If gender differences exist, then programs or curriculum developed to decrease weight-based stigmatization should use different approaches with male and female children. It is also necessary to include how age and gender are related since gender-segregated play decreases as children become older, which may also cause changes to male and female children's perceptions of overweight children especially when dating and romantic relationships begin.

\section{Children's Rationale for their Perceptions}

When children were asked to explain their rationale for choosing target figures as 'mean' or 'nice' many children justified their choice of 'mean' by pointing out aspects of target figures' physical attributes, behavioural attributes, and emotional attributes. As seen through the quantitative analysis, children rated overweight target figures as 'mean' more often than 'nice' and rated non-overweight target figures as 'nice' more often than 'mean'.

Children often justified choosing the overweight child as 'mean' due to their physical attributes. Children's rationales included observing that the overweight child was "bigger" or fatter" and pointing out body parts such as "a fatter belly" or "shorter arms" and overweight target figures' "bigger" clothing. Although these are physical attributes, children associated these attributes with being 'mean'. This is consistent with research that has shown that young children tend to focus on external attributes of people (Powlishta et al., 1994). Based on these findings, overweight children may be greatly stigmatized due to their physical attributes. As preschool children in the current study have associated being fat with being mean, children should be taught that size, body parts, and clothing do not determine the worth of an individual. Preschool children should be taught that although overweight children may be different in terms of body 
size, it does not mean that they are different than non-overweight children on other dimensions such as being nice.

Another common rationale children used for choosing target figures as 'mean' or 'nice' was based on behavioral attributes of the target figures. The majority of children chose the overweight child as the 'mean' child and this was justified by saying that overweight figures treated others badly, were often bullies, and were selfish individuals. These are very negative stereotypes towards overweight children that preschool children already possess. Therefore, even preschool children must be educated and be aware that not all overweight children are mean, bullies or are selfish. Perhaps the media can portray overweight characters as protagonists more often in story books, movies, and television to decrease the negative stereotypes against overweight children.

Finally, children rationalized their choice by pointing out emotional attributes of overweight children. Overweight children were chosen as 'mean' more often than 'nice' because they were perceived to look angrier than non-overweight target figures who looked happy. This was a very interesting finding since no facial features were present on target figures. Therefore children in the study used body size as their cue to predict happiness or anger in an individual. Other children stated that overweight children were 'mean' because they were often jealous. Interestingly, one child noted that the overweight child was the 'nice' child because the nonoverweight child was teasing the overweight child for being "fat". This illustrates that this preschool child is aware of stigmatization that overweight children face. Also, perhaps overweight children were seen as "angry", "mad" and "jealous" due to being stigmatized by society. Therefore, children should be educated on the negative affects of stigmatization, 
potentially deterring them from exhibiting negative weight-based biases towards overweight children.

To date, there have been very few studies using qualitative measures to explore size stigmatization with preschool children. Therefore, the results are unique but consistent with quantitative stories which have confirmed the existence of negative perceptions against overweight children. By understanding more about why overweight children are perceived negatively through the eyes of other children, researchers can develop a greater comprehension of how to change these negative perceptions. Since the study has shown that children perceive overweight children differently due to physical, behavioural and emotional attributes, these areas can be explored further and may inform preschool and elementary school curriculum.

\section{Recommendations for Weight Acceptance}

Working within the framework of Bronfenbrenner's social ecology theory, changes need to be made in children's environments in order to decrease negative perceptions of overweight children. Therefore, the following section will highlight practical changes that can be made in the different levels of children's environments to create lasting change to decrease stigmatization of overweight children. The findings of this study may help us to understand and influence children's environments to decrease weight-based stigmatization. In order to decrease weightbased stigmatization, adults and adults in charge of organizations for children (e.g., community centres, curriculum developers) must first be educated by researchers on the consequences of weight-based stigmatization and ways to prevent or decrease weight-based biases. Parents can create changes in their children's environments and teach them about body size acceptance in order to decrease the negative emotional and psychological consequences that overweight individuals suffer due to stigmatization. The following section will recommend practical tips that 
early childhood educators, teachers, parents and school boards can implement to decrease weight based stigmatization amongst children.

\section{Microsystems -Early Childhood Educators and Parents}

The results of the study have shown that children as young as two-and-a-half years old already hold negative perceptions against overweight children. Individuals within the Microsystem directly influence children, therefore they can help decrease children's weightbased biases. The literature has shown that teachers can be protective factors to children's perceptions of weight through interacting with their students constructively and offering corrective information regarding negative body weight and body shape attitudes. In order to be a protective factor, early childhood educators have to develop knowledge by critically evaluating perspectives and misconceptions, counter misconceptions and prejudices, and apply strategies and actions in the classroom to deter stigmatization. By critically evaluating school or preschool environments, student interactions, and classroom behaviors, early childhood educators and teachers can implement policies and intervene against stereotypical norms associated with different body sizes to create more inclusive schools. Piran (2004) argues that the "long-term goal is to create shifts that will allow teachers to work against transmitting the weightiest prejudice to students, and even more proactively, may allow teachers to actively work to counteract this prejudice" (p. 5).

The literature suggests that in order for classrooms to be fair and inclusive learning settings for students, early childhood educators and teachers need to be aware of their own prejudices and find ways to "utilize this greater consciousness to change relevant behaviors and attitudes" (Piran, 2004, p. 5). Early childhood educators must decrease weight based 
stigmatization in their classrooms and be "promot[ers] [of] respect and care for the body" to their students (Piran, 2004, pp. 5-6).

Since there are no strong pressures in society to eliminate anti-fat attitudes, in many cases when overweight children are stigmatized, adults do not intervene. Kostanski and Gullone (2007) indicate that when adults do not intervene and tolerate teasing based on weight, they are not only "engaging in the process themselves" but also "send a very powerful message that the use of hurtful words, surreptitious comments and harassment of others is an accepted part of growing up" (p. 317). Therefore, early childhood educators and teachers can decrease negative weightbased stigmatization amongst students by intervening when weight-based teasing occurs.

In addition, parents can also help decrease size discrimination. Research surrounding children's body image has often examined the relationship between body dissatisfaction in mothers and the effects of these attitudes on their children (Musher-Eizenman, Holub, EdwardsLeeper, Persson, \& Goldstein, 2003). In one research study, mothers who had more weight concerns had 5-year-old daughters who also had higher weight concerns than mothers who had less weight concerns (Davison, Markey \& Birch, 2000). In a qualitative study conducted by McCabe et al. 2007, mothers were interviewed and results were consistent with previous findings that demonstrated that mothers "communicate their weight concerns" and have concerns about muscle size and weight of their children as young as four years old (p. 228). It is recommended that parents could benefit from educational programs developed to target their own body image concerns that may propel body dissatisfaction and weight-stigmatization to their children.

Mesosystem - Home and School Environment

Bronfenbrenner's Mesosystem is composed of interrelated and connected settings that influence each other. The results of the current study showed that even preschool children have 
negative perceptions of overweight children. Therefore, in order for negative perceptions of overweight children to decrease, both school and home environments must work together to eliminate weight-based stigmatization. In the Very Important Kids (V.I.K) program designed by Haines et al. (2006) individual, environmental and family-based interventions were used to successfully decrease weight-based teasing and unhealthy weight-control behaviors. The results of the study showed the importance of positive effects of parental participation in prevention programs and emphasized "the importance of parental influence and support for the desired behavior change" (Haines et al., 2006). By using a multi-level approach, researchers expect that behaviours and attitudes of children will be impacted and remain relatively constant since there will also be a change of norms in children's environment (Haines et al., 2006).

In a different study conducted by Haines et al. (2007), focus groups and interviews were done with parents, teachers and children about promoting positive body image. Results showed that both parent and school staff believed that "program events should be for the whole family" (Haines et al., 2007). Future programs that emphasize positive body image, self-esteem and weight-based acceptance in children should be centered on the individual, family, and environment of children in order for lasting change to occur. In addition, based on results from this study and through past literature, differences in weight-based stigmatization due to gender should be more thoroughly examined and prevention or intervention may benefit from catering programs to decrease stigmatization specifically in boys and girls. By addressing the need for changes in parental attitudes about weight and engaging parents in prevention or intervention strategies, children will receive support both at school and at home to help children develop positive and healthy body images and acceptance of those with different body sizes. 


\section{Exosystem - School Boards}

The Exosystem is also an important system that can be changed to promote body size acceptance. In order for weight based stigmatization to decrease school boards must create and reinforce anti-weight based harassment policies. Researchers have argued that if children entering grade one are taught that it is unjust to reject others due to skin colour, religion, or disabilities, children can also be taught that weightism is equally harmful (Bardick, Bernes, McCulloch, Witko, Spriddle \& Roest, 2004). Larkin \& Rice (2005) recommend that "body equity" messages should be promoted within the school system in order to increase acceptance of diverse body sizes. While many schools have created policies that do not tolerate racism or sexism, body-based harassment is often not recognized. Therefore, schools should create zerotolerance policies against weight-based harassment in order for children to understand that stigmatization due to weight can be hurtful. In addition, since studies have consistently shown that weightism emerges in early childhood, these policies should begin to be put in place even in early childhood programs. The results of the study have shown that there were no significant differences in terms of age, however average scores across age groups show that negative perceptions towards overweight children increase with age. Based on this knowledge, weight bias prevention programs should focus on younger children, however, weight stigma should be addressed within school boards as well.

If early childhood educators, teachers, parents and school boards work together to increase weight acceptance, children's perceptions and negative opinions towards overweight children may decrease. 


\section{Macrosystem and Chronosystem - Mass Media}

This study has shown that preschool children have already begun to hold negative perceptions of overweight children. Therefore, in order for weight-based stigmatization to decrease, the mass media also needs to examine the weight stereotypes portrayed through television, movies, magazines and books. Perhaps more overweight protagonist characters can be incorporated into popular culture in order to show that overweight individuals also have positive characteristics. In addition, television shows, movies and books geared towards preschool children about diverse body sizes and weight acceptance may help decrease weight-based stigmatization. Therefore, with changes seen in children's social environments and over time, society may begin to value and accept different body sizes.

\section{Limitations of Study}

There are a number of limitations for the study. The first, due to the limited time frame of the study, opportunity sampling was used. Therefore, the results are not generalizable to other populations. The children that participated in the study attended ELCC within the Greater Toronto Area (GTA) therefore, the results may not be representative of preschool children outside of the GTA.

As well, previous research has shown that socioeconomic status is correlated with perceptions of obesity. Research has found that individuals of higher socioeconomic status tend to have more negative perceptions towards obesity (Turnbull, Heaslip \& McLeod, 2000). Therefore, socioeconomic status may have been a confounding factor that was not explored in this study. In future research, socioeconomic status should be included as a variable to understand how preschool children's socioeconomic status could be associated with their perceptions of overweight children. 
Also, due to ethical considerations, all data collection was conducted within the classroom. The activity was completed with the children during free time, since this was the most convenient time for early childhood educators. However, this sometimes served as a distraction for children participating in the activity. For example, in many instances, other children not involved in the study would come over to the child participating in the activity and watch as the child answered questions. This may have made children participating in the study feel uncomfortable or scrutinized and also may have influenced children to answer questions a certain way to increase their social desirability amongst their peers. In addition, in one centre, the teacher was present throughout the activity with the children, which may have also affected how the participants answered the questions.

Furthermore, this study cannot be directly compared to other similar studies since different measures were used. Although this study used Tillman et al.'s (2007) stories and pictures, the research instrument was slightly altered, where target figures faces were replaced with blank ovals, therefore, a direct comparison can not be made with Tillman's study due to potential differences in the research instrument.

\section{Recommendations for Future Research}

Latner et al. (2007) suggest that in order to make comparisons among different populations, "a measure standardized for more widespread use would permit investigations and comparisons of weight stigma across countries and cultures" (p. 3079). Therefore, it is recommended that in order for studies to be directly compared, to understand how age, gender, culture, geographical location or socioeconomic status are correlated with children's perceptions of weight, standardized measures need to be used to further inform and enrich our knowledge regarding weight stigmatization. 
Additionally, researchers have previously questioned whether measures of children's perceptions actually provide information about children's actual behaviour towards overweight individuals. Kraig \& Keel (2001) indicate that it is unknown how perceptions or attitudes may manifest into behaviours. Therefore, although children have negative perceptions of overweight children, it is not known if these same children with negative perceptions are stigmatizing overweight children. Research has shown that overweight children are stigmatized by their peers; however, the proportion of children with negative perceptions who actually behave negatively towards overweight children is not known. Research studying perceptions could benefit from using observational measures to better understand how and/or if children's negative perceptions manifest into negative outward actions towards overweight children.

Finally, this study looked solely at how weight contributes to perceptions, since both target figures were identical except for weight. However, Kraig \& Keel (2001) argue that asking participants to label target figures different only in weight "does not reflect how social evaluations naturally occur or how weight status may interact with other information to influence social evaluations" (p. 1665). For example, facial attractiveness may play a role in how children perceive overweight individuals (Counts et al., 1985). Future studies could explore how or if facial attractiveness or clothing style is associated with perceptions of overweight children.

There are still a plethora of unanswered questions regarding children's perceptions of overweight children that must continue to be explored through further research. Researchers have highlighted that universal prevention programs to decrease weight-based stigmatization may be more beneficial than intervention programs since it may be easier to encourage children to respect others regardless of weight than to change negative attitudes about weight that already exist in children. Therefore, research should continue to investigate the origins of weight-based 
stigmatization in order to understand how they develop and form, and also investigate ways to prevent negative associations with overweight individuals from forming. This would help create a society where overweight individuals do not face the negative stigmatization that they do today.

\section{Contributions of the Study}

The current study has contributed to the literature by examining young children's perceptions of overweight children. This is an important step in order to uncover an effective age for universal prevention programs to be introduced to children in order to prevent weight-based biases from developing. Although research should continue to explore the origin of weight-based stigmatization, this research with preschool children is a start and has contributed to the literature. As well, there have been few studies regarding body size stigmatization conducted with very young children; therefore, the current study has provided more information regarding preschool children's perceptions of weight. The study is significant because it shows the necessity for programming to combat weight-based stigmatization beginning in the early years.

In addition, many studies have solely been based on asking children to associate character traits or choose between overweight and non-overweight target figures, however few studies have examined children's rationales. This study has contributed to the literature because it has helped to understand why children perceived overweight children negatively through children's input. Thus, children's voices will be helpful in creating programming targeted towards body size acceptance since children have highlighted some factors that affect their perceptions of obesity. Therefore implementing programs which focus on the areas that children have outlined through their rationale, weight-based stigmatization may decrease. Studies in the future can 
continue to document children's voices in order to understand more factors which influence children's perceptions of obesity.

Finally, ethnicity has also been incorporated in this study. Studies in the literature have mainly focused on weight-based stigmatization of Caucasian middle class populations. Although this study was unable to examine if differences between cultures exist due to the sample size, this study has highlighted the diversity of the GTA. Therefore, this shows the necessity for research to continue to explore how children's attributions of weight are related to ethnicity. If children from different ethnicities perceive size differently, programming geared to decrease weightbased stigmatization should be created to benefit children of all ethnicities.

\section{Conclusion}

Body size acceptance is essential for children because body size stigmatization is related to many serious problems. Through this study, insights have been gained about how preschool children perceived other children who are overweight. The lessons learned from this study will help early childhood educators, teachers and parents create better strategies to address body size issues in early childhood programs, schools and home environments. Hopefully with more research, development and evaluation of programs, children can be positively influenced. By creating environments where all educators, parents, and children are accepting of each other regardless of race, culture, religion, gender, sexuality, disability and body size, an atmosphere of inclusion, acceptance, and belongingness for each child can be achieved. 



\section{Appendix A}

Board of Directors and/or Owner/Operator Letter of Information

Dear Operator/Owner/Board of Directors: Date:

I am a graduate student at Ryerson University in the Masters of Arts, Early Childhood Studies program and I am conducting a research study that is part of my Major Research Paper requirement, entitled, Preschool children's perceptions of other children based on weight. The purpose of the study is to explore how preschool children perceive children who are overweight and non-overweight. I am also interested in how gender, age, and culture play a role in children's perceptions of overweight or non-overweight children. The results from this research may benefit children by uncovering potential biases during the early years and using the results to inform preschool programming to decrease weight-based teasing and body dissatisfaction in children.

As a child care centre offering programs to preschool aged children I would like you to consider allowing your center to participate in this study.

What is involved in the Study?

i) Parents will be sent home an information letter along with a consent form explaining the study. Parents will make an informed decision of whether or not to allow their child to participate in the study. If parents decide they would like their child to participate in the study, parents will sign the consent form and fill out a short demographic questionnaire. The questionnaire will take no more than 5 minutes.

ii) After parental consent is received, I will book a time with the supervisor responsible for the day to day operation of the centre to visit the centre to conduct the activity. 
iii) At the start of the activity, I will ask the child if she/he would like to participate in the activity. If the child verbally agrees, then the activity will begin.

iv) The activity will involve the child hearing four short stories, looking at some pictures of target figures, and answering some short questions. The activity will take approximately 15 minutes to complete and will be in the child's classroom. Children may choose not the answer questions and may stop the activity at any time.

Participation is voluntary: Participation is completely voluntary and any participant may withdraw from the study at any time.

Risk: Because of the sensitive nature of the topic, a child may potentially reflect on unpleasant memories. However children may stop the activity at any time and return to his/her regularly scheduled activity. The child will be in the classroom and the teacher will also be present in the room.

Confidentiality: The data collected will be kept confidential and will be only accessed by the researcher and her supervisor, Dr. Aurelia Di Santo. Data will be coded numerically so that participants cannot be identified. The researcher will store the data, transcriptions and audiotapes in a confidential manner, in a locked filing cabinet in Dr. Aurelia Di Santo's office at Ryerson University for one year after which time they will be properly disposed. The results may also be presented in professional journals or at conferences, but any such presentations will be of general findings and will never breach individual confidentiality. 
Questions? If you have any questions about the study you may contact me, Wei Su by phone at (647) 283-6560 or by email at wei.su@ryerson.ca. Upon request, I can be available to meet with you at your centre.

Thank you very much for taking the time to review the study. If you would like for your centre to participate in this research, please sign the consent form that is attached to this letter and return it to your centre supervisor/director. The signed consent form is required for your centre to participate in the study. You may keep this letter for your records.

Thank you for your consideration.

Sincerely,

Wei Su

Wei Su

MA Candidate

Ryerson University

(647) 283-6560

wei.su@,ryerson.ca

Supervisor - Dr. Aurelia Di Santo

Ryerson University

School of Early Childhood Education

(416) 979-5000 ext 4576

disanto@ryerson.ca 

Appendix B

\section{Board of Directors or Owner/ Operator Consent Form}

Please read and sign this form

Name of Centre

I understand that has been asked to participate in a Name of Centre

research study entitled Preschool Children's Perceptions of other Children Based on Weight, conducted by Wei Su, MA Candidate at Ryerson University. I understand that participation is voluntary and that participants may withdraw from the study at any time.

As the owner/operator or Board of Directors of

I have read the attached information letter and agree to give my consent to allow the centre to participate in the research study __ (check $\sqrt{ }$ )

Name

Signature

Date

day/month/year

Phone Number

E-mail 

Appendix C

\section{Ryerson University \\ Parental Consent Agreement}

\section{Preschool Children's Perceptions of other Children Based on Weight}

Your child is being asked to participate in a research study. Before you give your consent for your child to be a volunteer, it is important that you read the following information and ask as many questions as necessary to be sure you understand what your child will be asked to do.

\section{Investigators:}

Wei Su, BAH, Master of Arts Candidate, Ryerson University Early Childhood Studies,. wei.su@ryerson.ca 647-283-6560

Purpose of the Study: The study will explore preschool aged children (age 3, 4, 5) perceptions of other children based on body size.

Description of the Study: The purpose of the proposed study is to understand how preschool children perceive other children based on body size. Four simple short stories about an interaction between two children will be told. The stories will be presented along with a picture of two target figures identical except for weight. Children will be asked to select figures to represent the characters in the story along with their rationale. The study will be conducted in the child's preschool classroom. The study will be conducted in a quiet area in your child's preschool classroom and will take 15 minutes to complete. With your permission, your child's responses during the activity will be tape recorded.

What is Experimental in this Study: None of the procedures used in this study are experimental in nature. The only experimental aspect of this study is the gathering of information for the purpose of analysis.

Risks or Discomforts: There are minimal risks associated with the activity however because of the sensitive nature of the topic, a child may reflect on unpleasant memories while responding to question. If this happens, your child may stop the activity at any time and return to his/her regularly scheduled activity. The activity will take place in your child's classroom and your child's teacher will also be present.

Benefits of the Study: The principal aim of the study is to examine preschool children's perceptions of overweight children. The findings may inform preschool and kindergarten curriculum targeted at eliminating weight-based teasing.

Confidentiality: The data will be kept confidential and will only be accessed by the researcher and her supervisor, Dr. Aurelia Di Santo. The researcher will store the data, transcriptions and audio-tapes in a confidential manner, in a locked filing cabinet in Dr. Aurelia Di Santo's office at Ryerson University for one year after which time they will be disposed. The results may also be 
presented in professional journals or at conferences, but any such presentations will be of general findings and will never breach individual confidentiality.

Voluntary Nature of Participation: Participation in this study is voluntary. Your choice of whether or not to participate will not influence your future relations with Ryerson University or your child's preschool program. If you decide your child can participate, you are free to withdraw your consent and to stop your child's participation at any time without penalty or loss of benefits to which you are allowed.

At any particular point in the study, your child may refuse to answer any particular question or stop participation altogether.

Questions about the Study: If you have any questions about the research, you may contact:

\author{
Wei Su \\ Student Researcher- \\ Master of Arts Candidate \\ Ryerson University \\ Early Childhood Studies \\ Telephone Number - (647) 283-6560 \\ Email Address - wei.su@,ryerson.ca \\ Supervisor - Dr. Aurelia Di Santo \\ Ryerson University \\ School of Early Childhood Education \\ Telephone Number - (416) 979-5000 ext 4576 \\ Email Address - disanto@ryerson.ca
}

If you have questions regarding your child's rights as a human subject and participant in this study, you may contact the Ryerson University Research Ethics Board for information.

Research Ethics Board

c/o Office of the Vice President, Research and Innovation

Ryerson University

350 Victoria Street

Toronto, ON M5B 2K3

416-979-5042 


\section{Agreement:}

Your signature below indicates that you have read the information in this agreement and have had a chance to ask any questions you have about the study. Your signature also indicates that you agree to allow your child to be in the study and have been told that you or your child can change your mind and withdraw your consent to participate at any time. You have been given a copy of this agreement.

Can your child's response be tape recorded? Yes

No

You have been told that by signing this consent agreement you are not giving up any of your legal rights.

Name of Child (please print)

Signature of Parent/Guardian

Date

The two-page information letter is for you to keep. If you agree to have your child participate in the activity, please return this agreement form along with the short questionnaire about your child's demographics to your child's teacher. 

Appendix D

Study Flyer

\title{
Dear Parents,
}

\section{Would you like your child to be involved in an exciting research study? \\ I am conducting a study that looks at preschool children's views about body size.}

\author{
Your child will participate in a short activity \\ which involves listening to four short stories \\ about children's interactions and answering \\ questions based on the story.
}

An information letter and consent form will be given to you. If you/and your child choose to participate, you can sign and return the consent form to your child's teacher.

Thank You!

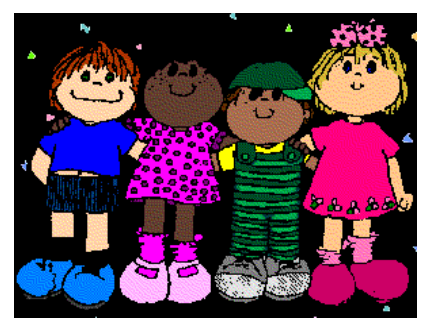

Wei Su

Master of Arts Candidate - Early Childhood Studies

Ryerson University

(647) 283-6560

e-mail: wei.su@ryerson.ca 

Appendix E

\section{Demographic Questionnaire of Child}

Please return this form with your consent form

1) Gender of Child Male

Female

2) Child's Date of Birth

\section{Date / Month / Year}

3) Please specify your ethnic background

(e.g., Canadian, Chinese, Cree, East Indian, Greek, Italian, Jamaican, Lebanese, Polish, Portuguese, Somali etc.)

Mother's ethnic background

Father's ethnic background

Thank you very much for your time and participation.

It is greatly appreciated!

Please return this questionnaire with your consent form

Wei Su

Masters of Arts Candidate

Early Childhood Studies

Ryerson University 

Appendix F

\section{Four Stories and Questions and Follow-Up Questions Tillman (2003)}

After children have given their assent to participate in the activity, story-telling will begin. The four short stories provided below will be told to children. At the end of each short story children will look at a picture of two target figures. The child will select a 'mean' child and a 'nice' child. Examples of follow-up questions are also provided. The researcher will allow themes to emerge from the conversation; however themes such as friendships with overweight children or weight biases may be explored during the follow-up questions.

\section{Story 1: Male, Fantasy}

John and Matt were walking alone in the forest. Matt said to John, "If you got lost I would come and find you". But John replied, "Well if you got lost, I'd go home and leave you all alone in the woods".

Which of these two boys is Matt, the nice one who said he would help his friend get out of the woods?

Which of these two boys is John, the mean one who said he would leave his friend in the woods?

\section{Follow-Up Questions:}

Why did you choose this child (researcher points to the figure chosen by the child) as the 'mean' child?

e.g Child answers: "This one is John. He's mean because he's big"

Researcher may ask: "Do you think that bigger people are meaner?"

Why did you choose this child (researcher points to the figure chosen by the child) as the 'nice' child?

\section{Story 2: Male, Realistic}

David and Tom sat near each other in their classroom. The teacher told all the students to find partners. David said, "I'd like to be your partner, Tom." But Tom said, "Well I don't like you and I never want to be your partner".

Which of these two boys is David, the nice one who wanted to be partners?

Which of these two boys is Tom, the mean one who said he didn't want to be partners?

Follow-Up Questions:

Why did you choose this child (researcher points to the figure chosen by the child) as the 'mean' child?

Why did you choose this child (researcher points to the figure chosen by the child) as the 'nice' child?

e.g Child answers: "This one is David because he looks like my brother" 
Researcher may ask: "Is your brother nice to you?"

\section{Story 3: Female, Fantasy}

Caroline and Sara were watching the circus. After the show they were both allowed to ride on top of the elephant. Sara nicely told Caroline to go ride the elephant first. But Caroline selfishly said, "I'm going to ride the elephant the whole time and you can't go at all".

Which of these two girls is Sara, the nice one who said she'd ride the elephant last? Which of these two girls is Caroline, the mean one who said she was going to ride the elephant the whole time?

Follow-up Questions:

Why did you choose this child (researcher points to the figure chosen by the child) as the 'mean' child?

Why did you choose this child (researcher points to the figure chosen by the child) as the 'nice' child?

e.g Child answers: "This is Sara, the nice one because she looks friendlier"

Researcher may ask: "What makes Sara look friendlier?"

\section{Story 4: Female, Realistic}

Amy and Laura went outside at the playground. Amy was very kind and let Laura use her favorite red bouncy ball. At the end of the outdoor time Amy said, "Could I have my ball back?" Laura said, "No" and dropped the ball into a puddle of mud.

Which of these two girls is Laura, the mean one who threw the ball in the mud?

Which of these two girls is Amy, the nice one who gave her ball to someone else?

\section{Follow-up Questions:}

Why did you choose this child (researcher points to the figure chosen by the child) as the 'mean' child?

e.g Child answers: "This is Laura because she looks mean"

Researcher may ask: "What makes Laura look mean?"

Why did you choose this child (researcher points to the figure chosen by the child) as the 'nice' child? 
Appendix G

Target Figures

Tillman (2003)
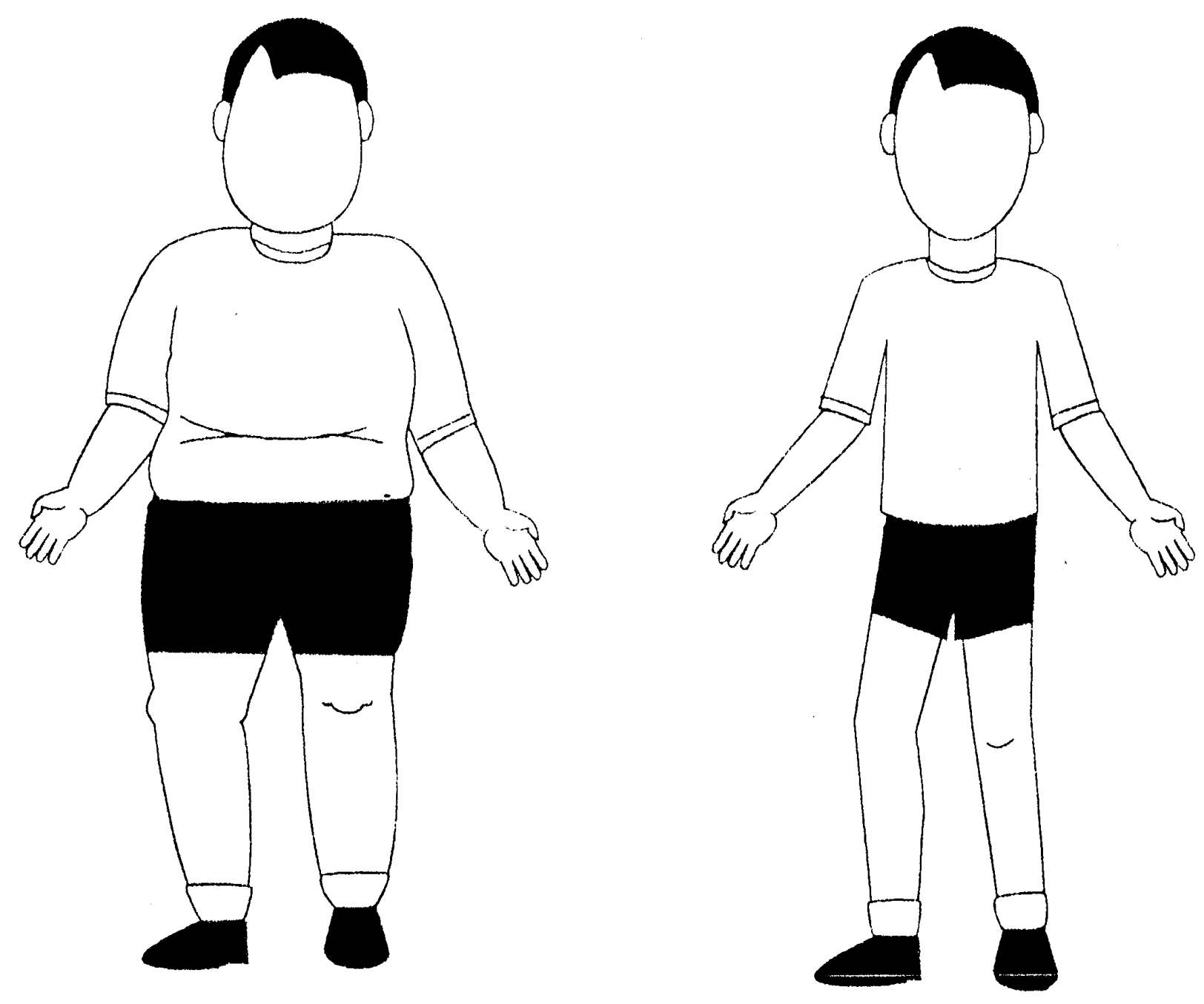

Figure 1. Obese and Non-Obese Target Pictures for the Male, Fantasy Story 

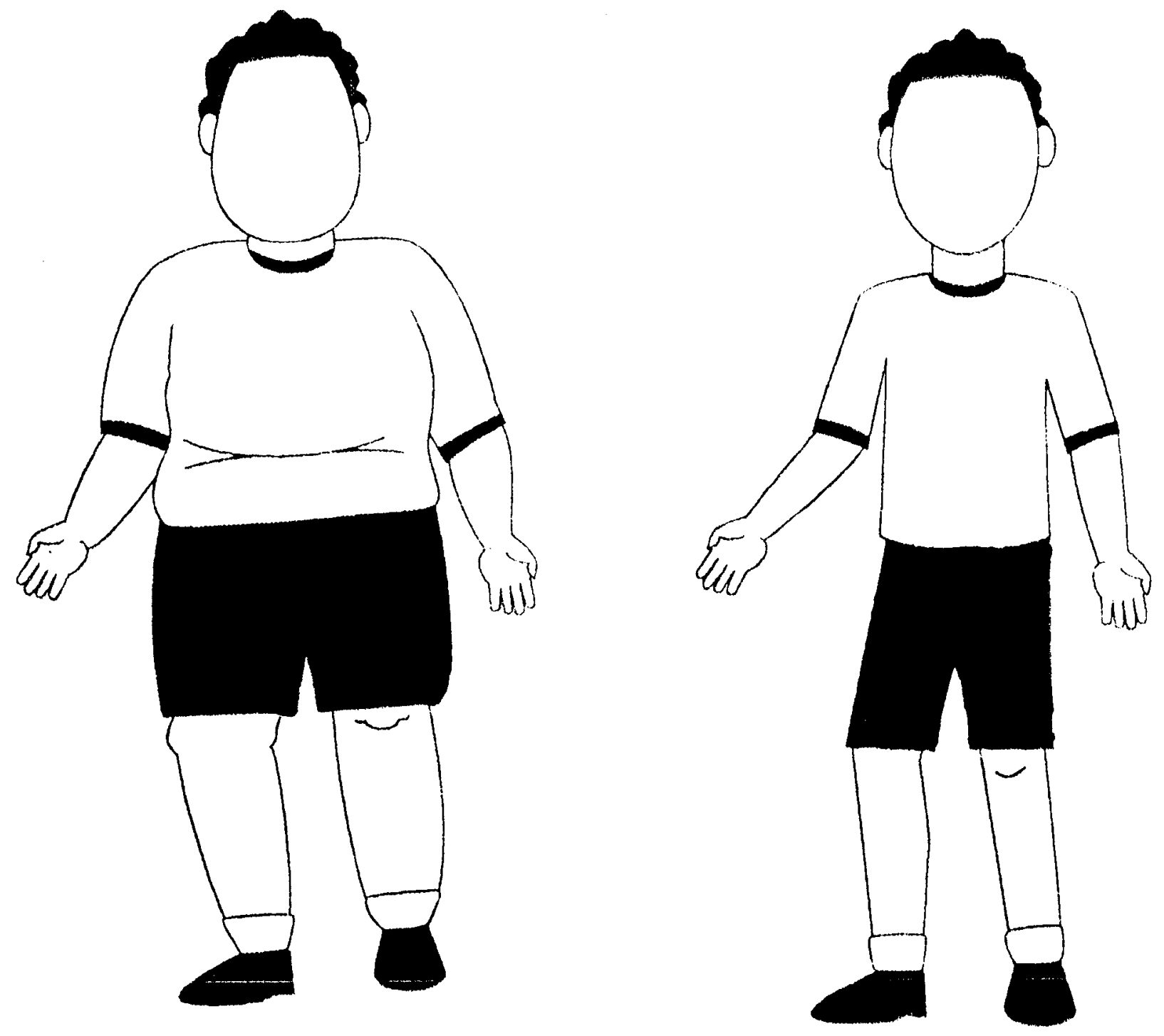

Figure 2. Obese and Non- Obese Target Pictures for the Male, Realistic Story 

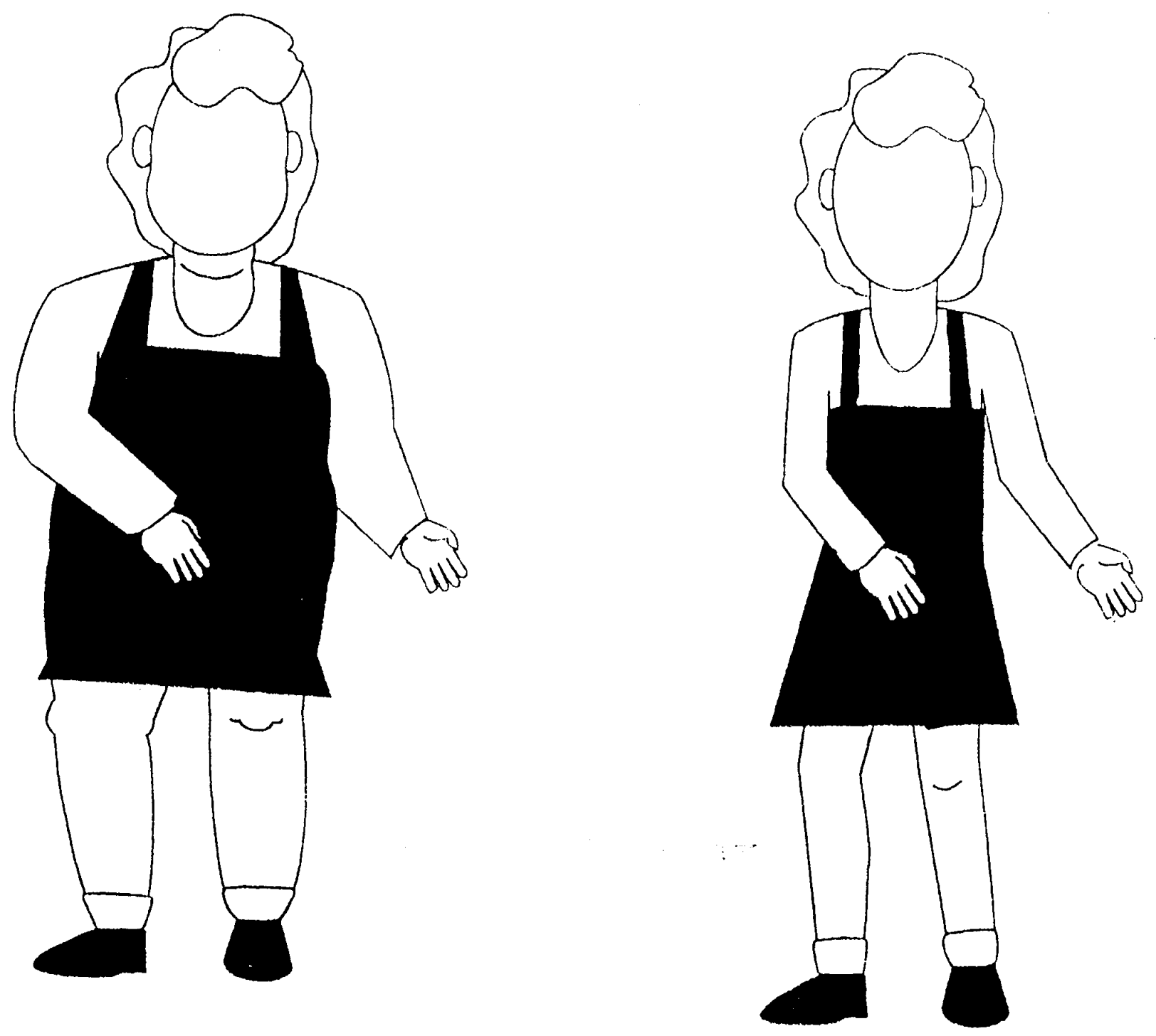

Figure 3. Obese and Non- Obese Target Pictures for the Female, Fantasy Story 

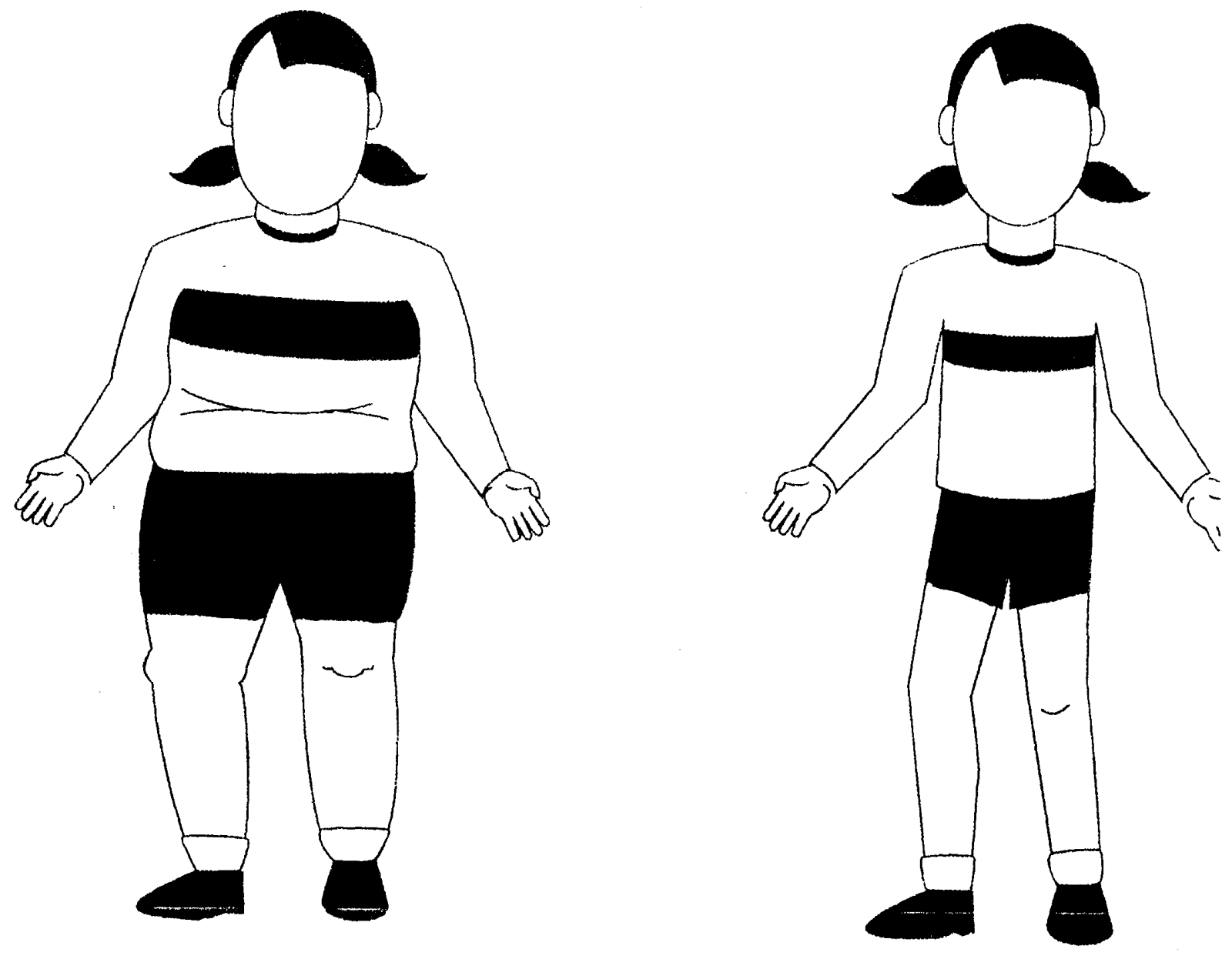

Figure 4. Obese and Non- Obese Target Pictures for the Female, Realistic Story 
Appendix $\mathbf{H}$

Permission from Tillman

\section{From: Tracy Tillman <tillmant@peabody.k12.ma.us> \\ Sent Wednesday, April 2, 2008 11:37 am \\ To Wei Su <wei.su@ryerson.ca> \\ Subject Re: Measures}

Hi Wei Su! I just got your phone message along with this e-mail. I am thrilled that you are interested in following up my dissertation findings with a preschool study. Please feel free to use any of the stories and/or pictures that will be helpful. If you have any questions please call or write at any time. I am curious to see what you find- best of luck! 


\section{References}

Bardick, A.D., Bernes, K.B., McCulloch, A.R.M., Witko, K.D., Spriddle, J.W. \& Roest, A.R. (2004). Eating disorder intervention, prevention and treatment: recommendations for school counselors. Professional School Counselling, 8, 168176.

Birbeck, D. \& Drummond, M. (2005). Interviewing, and listening to the voices of, very young children on body image and perceptions of self. Early Child Development and Care, 176, 579-596.

Brumberg, J.J. (1998). The body project: An intimate history of American girls. New York: Random House, 1998.

Canning, H., \& Mayar, J. (1966). Obesity: its possible effect on college acceptance. New England Journal of Medicine, 275, 1172-1174.

Clark, L., \& Tiggemann, M. (2007). Sociocultural influences and body image in 9-to-12 year-old girls: The role of appearance schemas. Journal of Clinical Child and Adolescent Psychology, 36, 76-86.

Counts, C.R., Jones, C., Frame, C.L., Jarvie, G.J., \& Strauss, C.C. (1986). The perception of obesity by normal-weight versus obese school-age children. Child Psychiatry and Human Development, 17, 113-120.

Cramer, P., \& Steinwert, T. (1998). Thin is good, fat is bad: How early does it begin? Journal of Applied Developmental Psychology, 19, 429-451.

Creswell, J.W. (2008) Educational Research: Planning, Conducting, and Evaluating Quantitative and Qualitative Research. (3 ${ }^{\text {rd }}$ ed.) New Jersey: Pearson Prentice Hall. 
Davison, K.K., Markey, C.N., 7 Birch, L.L. (2000). Etiology of body dissatisfaction and weight concerns among 5-year-old girls. Appetite, 35, 143-151.

Dixey, R., Sahota, P., Atwal, S., \& Turner, A. (2001). "Ha ha, you're fat, we're strong”; a qualitative study of boys' and girls' perceptions of fatness, thinness, social pressures and health using focus groups. Health Education, 101, 206-216.

Dockett, S. \& Perry, B. (2007). Trusting children's accounts in research. Journal of Early Childhood Research, 5, 47-63.

Favaro, A., Zanetti, T., Huon, G., \& Santonastaso, P. (2005). Engaging teachers in an eating disorder preventative intervention. International Journal of Eating Disorders, 38, 73-77.

Gardiner, H.W., \& Kosmitzki, C. (2008). Lives Across Cultures: Cross-Cultural Human Development $\left(4^{\text {th }}\right.$ ed.). Boston: Pearson Education, Inc.

Ghaderi, A., Martensson, M., \& Schwan, H. (2005). "Everybody's Different”: A primary prevention program among fifth grade school children. Eating Disorders, 13, 245 259.

Goodman, M., Dornbusch, S.M., Richardson, S.A.,\& Hastorf, A.H. (1963). Variant reactions to physical disabilities. American Sociological Review, 28, 429-435.

Gray, P. (2002). Psychology (4 ${ }^{\text {th }}$ ed.). New York: Worth Publishers.

Greenleaf, C., \& Weiller, K. (2005). Perceptions of youth obesity among physical educators. Social Psychology of Education, 8, 407-423.

Grogan, S. (2008). Body image understanding body dissatisfaction in men, women, and children. London and New York: Routledge.

Hague, A., L., \& White, A.A. (2005). Web-based intervention for changing attitudes 
among current and future teachers. Journal of Nutritional Education and Behavior, 37, 58-66.

Haines, J., Neumark-Sztainer, D., Perry, C.L., Hannan, P.J., \& Levine, M.P. (2006). V.I.K. Very Important Kids): a school-based program designed to reduce teasing and unhealthy weight-control behaviors. Health Education Research, 21, 884895.

Haines, J., Neumark-Sztainer, D., \& Thiel, L. (2007). Addressing weight-related issues in an elementary school: what do students, parents, and school staff recommend? Eating Disorder Journal Treatment and Prevention, in press.

Harrison, K. (2000). Television viewing, fat stereotyping, body shape standards, and eating disorder symptomatology in grade school children. Communication Research, 27, 617-640.

Hayden-Wade, H.A., Stein, R.I., Ghaderi, A., Saelens, B.E., Zabinksi, M.F., \& Wilfley, D.E. (2005). Prevalence, characteristics, and correlates of teasing experiences among overweight children vs. non-overweight peers. Obesity Research, 13, 1381-1392.

Heyman, G.D., \& Gelman, S.A. (1999). The use of trait labels in making psychological inferences. Child Development, 70, 604-619.

Hill, M. (2005). Ethical consideration in researching children's experiences. In S. Greene, \& D. Hogan (Eds.), Researching Children's Experience: Approaches and Methods (pp.22- 41). Sage Publications Ltd.

Jansen, A., Smeets, T., Boon, B., Nederkoorn, C., Roefs, A., \& Mulkens, S. (2007). Vulnerability to interpretation bias in overweight children. Psychology and 
Health, 22, 561-574.

Jarvie, G. L., Lahey, B., Graziano, W., \& Framer, E. (1983). Childhood obesity and social stigma: What we know and what we don't know. Developmental Review, 3, 237-273.

Jarvie, G. L. (1984). The influences of body build on social approach in the ninth grade. Paper presented to Biennial Meeting of the Southeastern Conference on Human Development, Athens, Georgia, 1984.

Jung, J., \& Peterson, M. (2007). Body dissatisfaction and patterns of media use among preadolescent children. Family and Consumer Sciences Research Journal, 36, $40-54$.

Kostanski, M., \& Gullone, E. (2007). The impact of teasing on children's body image. Journal of Child and Family Studies, 16, 307-319.

Kraig, K.A., \& Keel, P.K. (2001). Weight-based stigmatization in children. International Journal of Obesity, 25, 1661-1666.

Larkin, J., \& Rice, C., (2005). Beyond "healthy eating" and "healthy weights":

Harassment and the health curriculum in middle schools. Body Image, 2, 219232.

Latner, J.D., \& Stunkard, A.J. (2002). Getting worse: The stigmatization of obese children. Obesity Research, 11, 452-456.

Latner, J.D., Simmonds, M., Rosewall, J.K., \& Stunkard, A.J. (2007). Assessment of obesity stigmatization in children and adolescents: Modernizing a standard measure. Obesity Research, 15, 3078-3084.

Latner, J.D., Stunkard, A.J., \& Wilson, G.T. (2005). Stigmatized students: Age, sex, and 
ethnicity effects in the stigmatization of obesity. Obesity Research, 13, 12261231.

Lerner, R.M., \& Korn, S.J. (1972). The development of body-build stereotypes in males. Child Development, 43, 908-920.

Lunde, C., Frisen, A., \& Hwang, P. C. (2006). Is peer victimization related to body esteem in 10-year-old girls and boys? Body Image, 3, 25-33.

MacDermott, J.S. (2007). The stigma of childhood obesity: A literature review. (Doctoral Dissertation, University of Hartford). Dissertations Abstracts International, 61, 7027.

McCabe, M.P., Ricciardelli, L. A., Stanford, J., Holt, K., Keegan, S., \& Miller, L. (2007) Where is all the pressure coming from? Messages from mothers and teachers about preschool children's appearance, diet and exercise. European Eating Disorders Review, 15, 221-230.

Miller, C.T., Rothblum, E.D., Barbour, L., Brand, P.A., \& Felicio, D. (1990). Social interactions of obese and nonobese women. Journal of Personality, 58, 365-380.

Mullen, M. C., \& Shield, J. (2004). Childhood and adolescent overweight: The health professional's guide to identification, treatment, and prevention. American Dietetic Association.

Musher-Eizenman, D.R., Holub, S.C., Edwards-Leeper, L., Person, A.V., \& Goldstein, S.E. (2003). The narrow range of acceptable body types of preschoolers and their mothers. Applied Developmental Psychology, 24, 259-272.

Neumark-Sztainer, D., Story, M., \& Harris, T. (1999). Beliefs and attitudes about obesity among teachers and school health care providers working with adolescents. 
Journal of Nutrition Education and Behavior, 31, 3-9.

O’Dea, J. (2002). Can body image education programs be harmful to adolescent females? Eating Disorders, 10, 1-13.

Pine, K. J. (2001). Children's perceptions of body shape: A thinness bias in preadolescent girls and associations with femininity. Clinical Child Psychology and Psychiatry, 6, 519-536.

Piran, N. (2004). Teachers: On "being" (rather than "doing") prevention. Eating Disorders, 12, 1-9.

Pitman, T., \& Kaufman, M. (2000). The Over Weight Child: Promoting Fitness and SelfEsteem. New York: Firefly Books (U.S.) Inc.

Powdermarker, H. (1997). An anthropological approach to the problem of obesity. Food And Culture: A Reader. Ed. Carole Counihan and Penny van Esterik. New York: Routledge.

Powlishta, K.K., Serbin, L.A., Doyle, A.B., \& White, D.R. (1994). Gender, ethnic, and body type biases: The generality of prejudice in childhood. Developmental Psychology, 30, 526-536.

Raine, K.D. (2004). Overweight and obesity in Canada: a population health perspective. Canadian Institute for Health Information. Retrieved August 1, 2008, from http://secure.cihi.ca/cihiweb/products/CPHIoverweightandobesityAugust2004_e.pdf Richardson, S.A., Goodman, N., Hastorf, A.H., \& Dornbusch, S.M. (1961). Cultural uniformity in reaction to physical disabilities. American Sociological Review, 26, 241-247.

Ruble, D.N., \& Dweck, C.S. (1995). Self-conceptions, person conceptions and their 
development. In N. Elsenberg (Ed.), Review of personality and social psychology: Vol. 15. Social development (pp. 109-139). Thousand Oaks, CA: Sage.

Schwartz, M.B., Chambliss, H.O., Brownell, K.D., Blair, S.N., \& Billington, C. (2003). Weight bias among health professionals specializing in obesity. Obesity Research, 11, 1033-1039.

Schwimmer, J.B., Burwinkle, T.M., \& Varni, J.W. (2003). Health-related quality of life of severely obese children and adolescents. The Journal of American Medical Association, 289, 1813-1819.

Siegler, R., Deloache, J., \& Eisenberg, N. (2003). How Children Develop. New York: Worth Publishers.

Sigelman, C.K., Miller, T.E., \& Whitworth, L.A. (1986). The early development of stigmatizing reactions to physical differences. Journal of Applied Developmental Psychology, 7, 17-32.

Skelton, J.A., Busey, S.L., \& Havens, P.L. (2006). Weight and health status of inner city African American children: Perceptions of children and their parents. Body Image, 3, 289-293.

Smolak, L. (1999). Elementary school curricula for the primary prevention of eating problems. In N. Piran, M. Levine, \& C. Steiner-Adiar (Eds)., Preventing eating Disorders: A handbook of interventions and special challenges (pp. 85-104). Philadelphia: Brunner/Mazel.

Smolak, L (2004). Body image in children and adolescents: Where do we go from here? Body Image, 1, 15-28.

Smolak, L., \& Levine, M.P. (2001). A two-year follow-up of a primary prevention 
program for negative body image and unhealthy weight regulation. Eating Disorders, 9, 313-325.

Snethen, J.A., \& Broome, M.E. (2007). Weight, exercise, and health: Children's perceptions. Clinical Nursing Research, 16, 138-152.

Snyder, M., Tanke, E.D., \& Berscheid, E. (1977). Social perceptions and interpersonal behavior on the self-fulfilling nature of social stereotypes. Journal of Personality and Social Psychology, 35, 656-666.

Staffieri, J.R. (1967). A study of social stereotype of body image in children. Journal of Personality and Social Psychology, 7, 101-104.

Stuass, C., Smith, K., Frame, C., \& Forehand, R. (1985). Personal and interpersonal characteristics with childhood obesity. Journal of Pediatric Psychology, 10, 337 343.

Stunkard, A.J., \& Sobal, J. (1995). Psychosocial Consequences of Obesity, in Eating Disorders and Obesity: A Comprehensive Handbook, eds. Brownwell, K.D., \& Fairburn, C.G. New York: The Guilford Press.

Teachman, B.A., Gapinski, K.D., Brownell, K.D., Rawlins, M. \& Jeyaram, S. (2003). Demonstrations of implicit anti-fat bias: the impact of providing causal information and evoking empathy. Health Psychology, 22, 66-78.

Thompson, J.K., Coovert, M.D., Richards, K.J., Johnson, S., \& Cattarin, J. (1995). Development of body image, eating disturbances, and general psychological functioning in female adolescents: Covariance structure modeling and longitudinal investigations. International Journal of Eating Disorders, 18, 221-236. 
Tiggemann, M., \& Anesbury, T. (2000). Negative stereotyping of obesity in children: the role of controllability beliefs. Journal of Applied Social Psychology, 30, 1977-1993.

Tillman, T. (2003). The perceptions of elementary school age children towards overweight peers. (Doctoral Dissertation, University of Connecticut). Dissertation Abstracts International, 64, 4361.

Tillman, T., Kehle, T.J., Bray, M.A., Chafouleas, S.M., \& Grigerick, S. (2007). Elementary school students' perceptions of overweight peers. Canadian Journal of School Psychology, 22, 68-80.

Turnbull, J. D., Heaslip, S., \& McLeod, H. A. (2000). Pre-school children's attitudes to fat and normal male and female stimulus figures. International Journal of Obesity, 24, 1705-1706.

Wardle, J., \& Beales, S. (1986). Restraint, body image and food attitudes in children from 12 to 18 y. Appetite, 7, 209-217.

Welch, C., Gross, S.M., Bronner, Y., Dewberry-Moore, N., \& Paige, D.M. (2004). Discrepancies in body image perception among fourth-grade public school children from urban, suburban, and rural Maryland. Journal of the American Dietetic Association, 104, 1080-1085.

Wills, W., Backett-Milburn, K., Gregory, S., \& Lawton, J. (2006). Young teenagers' perceptions of their own and others' bodies: A qualitative study of obese, overweight and 'normal' weight young people in Scotland. Social Science \& Medicine, 62, 396-406.

Wood, K.C., Becker, J.A., \& Thompson, J.K. (1996). Body image dissatisfaction in 
preadolescent children. Journal of Applied Developmental Psychology, 17, 85100.

World Health Organization. (n.d.).Obesity and Overweight. Retrieved July 25, 2008, from http://www.who.int/dietphysicalactivity/publications/facts/obesity/en/ 
